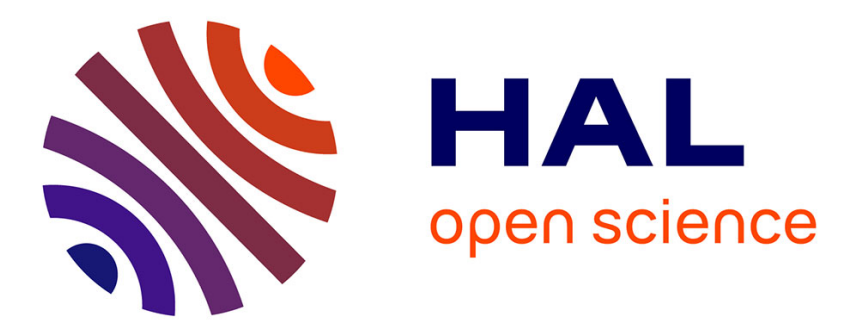

\title{
Design of concentrated colloidal dispersions of iron oxide nanoparticles in ionic liquids: structure and thermal stability from 25 to $200 " \mathrm{C}$
}

J C Riedl, M Sarkar, T Fiuza, F Cousin, J Depeyrot, Dubois Emmanuelle, G Mériguet, R Perzynski, V Peyre

\section{To cite this version:}

J C Riedl, M Sarkar, T Fiuza, F Cousin, J Depeyrot, et al.. Design of concentrated colloidal dispersions of iron oxide nanoparticles in ionic liquids: structure and thermal stability from 25 to 200 "C. Journal of Colloid and Interface Science, 2022, 607, pp.584-594. 10.1016/j.jcis.2021.08.017 . hal-03449992

\section{HAL Id: hal-03449992 https://hal.science/hal-03449992}

Submitted on 25 Nov 2021

HAL is a multi-disciplinary open access archive for the deposit and dissemination of scientific research documents, whether they are published or not. The documents may come from teaching and research institutions in France or abroad, or from public or private research centers.
L'archive ouverte pluridisciplinaire $\mathbf{H A L}$, est destinée au dépôt et à la diffusion de documents scientifiques de niveau recherche, publiés ou non, émanant des établissements d'enseignement et de recherche français ou étrangers, des laboratoires publics ou privés. 


\section{Graphical Abstract}

Design of concentrated colloidal dispersions of iron oxide nanoparticles in ionic liquids: structure and thermal stability from 25 to $200^{\circ} \mathrm{C}$

J. C. Riedl,M. Sarkar,T. Fiuza,F. Cousin,J. Depeyrot,E. Dubois,G. Mériguet,R. Perzynski,V. Peyre

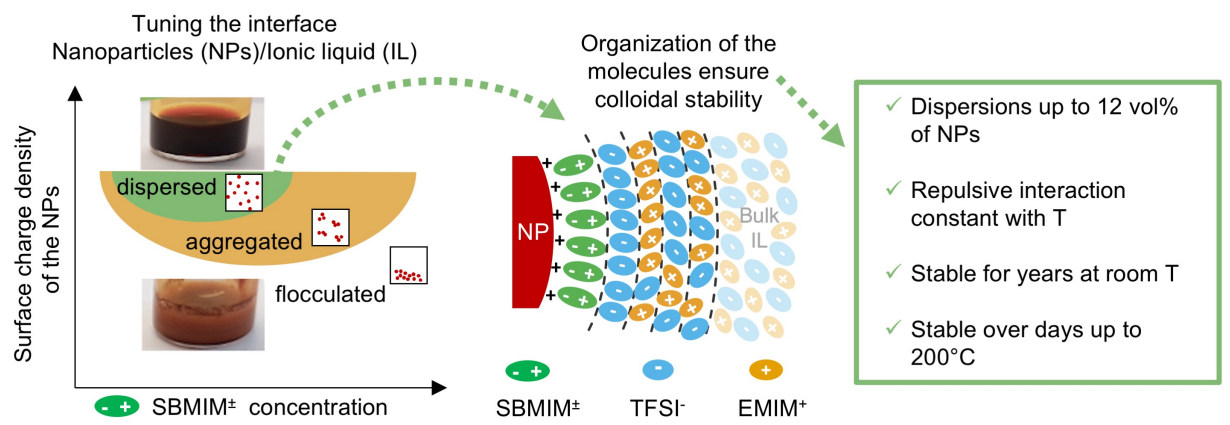




\title{
Design of concentrated colloidal dispersions of iron oxide nanoparticles in ionic liquids: structure and thermal stability from 25 to $200^{\circ} \mathrm{C}$
}

\author{
J. C. Riedl ${ }^{a}$, M. Sarkar ${ }^{a}$, T. Fiuza ${ }^{a, b}$, F. Cousin ${ }^{c}$, J. Depeyrot ${ }^{b}$, E. Dubois ${ }^{a, *}$, G. Mériguet ${ }^{a}$, \\ R. Perzynski ${ }^{b}$ and V. Peyre ${ }^{b, *}$ \\ ${ }^{a}$ Sorbonne Université, CNRS, Laboratoire PHENIX, 4 place Jussieu, case 51, 75005, Paris, France. \\ ${ }^{b}$ Inst. de Fisica, Complex Fluid Group, Universidade de Brasília, Brasília, Brazil \\ ${ }^{c}$ Laboratoire Léon Brillouin, UMR 12 CNRS-CEA, CEA-Saclay, 91191, Gif-sur-Yvette, France.
}

\section{ARTICLE INFO}

\section{Keywords:}

Colloidal dispersions

Ionic liquids

Nanoparticles

Nanofluids

Ionanofluids

\begin{abstract}
A B S T R ACT
Hypothesis: Some of the most promising fields of application of ionic liquid-based colloids imply elevated temperatures. Their careful design and analysis is therefore essential. We assume that tuning the structure of the nanoparticle-ionic liquid interface through its composition can ensure colloidal stability for a wide temperature range, from room temperature up to $200^{\circ} \mathrm{C}$.

Experiments: The system under study consists of iron oxide nanoparticles (NPs) dispersed in ethylmethylimidazolium bistriflimide (EMIM TFSI). The key parameters of the solid-liquid interface, tuned at room temperature, are the surface charge density and the nature of the counterions. The thermal stability of these nanoparticle dispersions is then analysed on the short and long term up to $200^{\circ} \mathrm{C}$. A multiscale analysis is performed combining dynamic light scattering (DLS), small angle $\mathrm{X}$-ray/neutron scattering (SAXS/SANS) and thermogravimetric analysis (TGA).

Findings: Following the proposed approach with a careful choice of the species at the solid-liquid interface, ionic liquid-based colloidal dispersions of iron oxide NPs in EMIM TFSI stable over years at room temperature can be obtained, also stable at least over days up to $200^{\circ} \mathrm{C}$ and NPs concentrations up to $12 \mathrm{vol} \%(\approx 30 \mathrm{wt} \%)$ thanks to few near-surface ionic layers.
\end{abstract}

\section{Introduction}

Ionic liquids (ILs) have a variety of properties such as high electrochemical and thermal stabilities, low vapour pressures, their abilities to dissolve many chemical species, and modest conductivities making them interesting for several fields of applications. Some examples are found in synthesis and catalysis processes [1], seals and bearings[2], as well as energy related applications $[3,4]$ such as batteries, supercapacitors and thermoelectric applications $[5,6,7]$. However, ionic liquids also have some properties hindering their

Abbreviations: ILs, Ionic liquids; NPs: nanoparticles; MD: molecular dynamics; $\sigma$, solid's surface charge density; $\Theta_{\text {ion }}^{\max }$, maximum charge density of a densely packed counterion monolayer; EMIM TFSI, ethylmethylimidazolium bistriflimide; DLS, Dynamic Light Scattering; SAXS, Small Angle X-Ray Scattering; SANS, Small Angle Neutron Scattering; TEM, Transmission electron microscopy, TGA, thermogravimetric analysis; $\Phi_{\mathrm{NP}}$, nanoparticle's volume fraction; FAAS, flame atomic absorption spectroscopy; ESI-MS, electrospray ionization mass spectrometry; $\mathrm{S}(\mathrm{Q})$, structure factor; $\chi$, osmotic compressibility; HTfO, triflic acid; HTFSI, N,N-Bis(trifluoromethanesulfonyl)imide acid; HSBMIM TFSI, 1(4-Sulfobutyl)-3-methylimidazolium bistriflimide; HSBMIM TfO, 1-(4Sulfobutyl)-3-methylimidazolium triflate; $\mathrm{SBMIM}^{ \pm}$, deprotonated form of HSBMIM $^{+}$, SFA, Surface Force Apparatus.

${ }^{*}$ Corresponding authors

jesseriedl@web.de (J.C. Riedl); mitradeep.sarkar@gmail.com (M.

Sarkar); thiagofiuza91@gmail .com (T. Fiuza); fabrice. cousin@cea. fr (F. Cousin); jerome. depeyrot@gmail.com (J. Depeyrot);

emmanuelle. dubois@sorbonne-universite. fr (E. Dubois); guillaume.meriguet@sorbonne-universite. fr (G. Mériguet);

regine.perzynski@sorbonne-universite.fr (R. Perzynski);

veronique. peyre@sorbonne-universite. $\mathrm{fr}$ (V. Peyre)

ORCID(s): $0000-0001-9361-5132$ (J.C. Riedl); $0000-0002-3431-0678$ (M. Sarkar); $0000-0001-8859-0460$ (T. Fiuza); $0000-0001-7523-5160$ (F. Cousin); 0000-0002-1689-573X (J. Depeyrot); 0000-0001-8554-8486 (E. Dubois); 0000-0002-9921-0395 (G. Mériguet); 0000-0002-6634-6245 (R. Perzynski); 0000-0002-5129-1544 (V. Peyre) industrial employment in some fields. For example they generally show elevated viscosities compared to molecular solvents which is connected to poor mass transport properties limiting the performance in energy applications at room temperature $[3,7]$. However, the viscosity reduces significantly when the ionic liquids are heated up whereby this disadvantage (almost) vanishes [8]. Therefore, the use of ionic liquids at elevated temperatures is extremely interesting for applications. In addition, the performance of electrochemical devices is improved with increasing temperature. A way to further improve the system's properties at low and higher temperatures can be the addition of nanoparticles (NPs) to ionic liquids [9]. The addition of charged nanoparticles to electrolytes of electrochemical devices can, for instance, improve the thermoelectric properties compared with the solvent alone [10] or improve electrochemical performance compared with the pure IL [11]. Such dispersions of NPs can also be considered as potential heat transfer fluids thanks to their improved thermal properties $[12,13]$. Other applications as the determination of ILs viscosities can be envisaged [14].

The colloidal stability of nanoparticle dispersions in ionic liquids can result from (i) polymers or molecules grafted on the NPs, (ii) molecules adsorbed on the NPs, (iii) the organization of the pure IL close to the NPs [9]. Among these options, the third one is privileged along with the addition of a small amount of species that can adsorb on the NPs. Indeed ion layering of the ionic liquid at the interface together with molecules that can absorb on the nanoparticle can produce a repulsive (oscillatory) force that can outrank the attractive van der Waals forces between the nanoparticles and therefore 
colloidal stability is obtained $[15,16,17,18,19,20]$. Such an ionic layering was shown by molecular dynamics (MD) simulations [15] and X-ray pair distribution analysis [16] of nanoparticle dispersions in molten salts ${ }^{1}$ and some ionic liquids. However, this layered organization has been essentially studied on flat surfaces like sapphire, mica or gold for which many experiments like atomic force microscopy or X-Ray reflectivity are easier to perform $[21,22]$. Elements of rationalization of the process have been brought by MD simulations of ionic liquids on flat surfaces, evidencing the crucial role of the ratio $\kappa_{\text {ion }}=\left|\sigma / \Theta_{\text {ion }}^{\max }\right|$ with $\sigma$ the solid's surface charge density and $\Theta_{\text {ion }}^{\max }$ the maximum charge density of a densely packed counterion ${ }^{2}$ monolayer [23]. For oxide NPs, $\sigma$ can be tuned in a limited range changing the acidity of the medium or the nature of the surface. On the other hand, the counterions can be changed in the system, either by changing the ionic liquid itself or by adding ions.

Several works analysing ionic-liquid based colloids evidenced that these additional ions influence the colloidal stability despite their low concentration as compared to the ions concentration in the ionic liquid $[18,19,24,25,26]$. Furthermore, the nanostructure of the IL in contact with chargeable flat surfaces like graphite [27] or gold [28] is observed to be modified when adding extra small ions like $\mathrm{Li}^{+}$or $\mathrm{Cl}^{-}$. These ions (even at low concentrations) have an influence as they can locate at the interface.

Besides, a long-range repulsion has been evidenced in ionic liquids and concentrated salt solutions [29,30] by SFA force measurements between charged plates in various ILs. This repulsion, the mechanism of which is still under debate, extends over distances larger than the few layers formed close to the surface. Typically, the characteristic distance of this long-range repulsion is $\simeq 7 \mathrm{~nm}$ at room temperature for EMIM TFSI between two symmetrical mica surfaces [30]. These forces, consistent with thermal disruption of electrostatic correlations and/or effective dissociation of ionic liquid ions, are closely related to the correlations induced in the presence of the charged surfaces in the bulk IL phase. However they are not well understood even in the most common conditions studied, at room temperature. Increasing temperature can have opposite effects on the different contributions, depending on their entropic or enthalpic nature [30]. Experimentally, the long range repulsion has been observed to depend on temperature and on IL nature, but in an equivocal manner: e.g. it decreases for mica surfaces in EMIM TFSI between 20 and $50^{\circ} \mathrm{C}$ [31] whereas it increases or even appears for silica/mica surfaces in ethylammonium nitrate (EAN) between room temperature and $120^{\circ} \mathrm{C}$ [32].

The use of ionic liquids at elevated temperatures is however extremely interesting for applications for example in the fields of heat transfer fluids [13], lubricants [33] or supercapacitors [11]. To be suitable, the ionic liquid-based systems need to be long-term stable at high temperature. This implies both chemical stability of the IL and colloidal stability of dispersions therein. Few studies have been performed above

\footnotetext{
${ }^{1}$ analogue of ionic liquids with a melting temperature above $100^{\circ} \mathrm{C}$

${ }^{2}$ ions of opposite charge compared to the surface
}

room temperature and fewer tried to analyze the nanostructure, both for ILs close to interfaces or for colloidal dispersions. Silica NPs dispersed in BMIM $\mathrm{BF}_{4}$ were studied up to $60{ }^{\circ} \mathrm{C}$, showing a change in interactions and rheological properties [34]. At higher temperature, only few nanoparticles in molten salts have been recently studied by Dynamic Light Scattering (DLS) on a range of temperature above their melting point [35].

Literature provides the decomposition temperature of the ILs in the short term, i.e. from classical thermogravimetric analysis (TGA) ramps, for a range of systems [36]. ILs based on fluorinated $\mathrm{BF}_{4}^{-}$, $\mathrm{TFSI}^{-}$or $\mathrm{TfO}^{-}$anions are among the most stable systems. After first measurements in several ILs based dispersions at high temperature ${ }^{3}$, EMIM TFSI was chosen for a more focused study. This is indeed one of the most stable ILs, largely studied in literature because of its low viscosity [37].

In this work, the colloidal stability of NPs dispersions of (magnetic) iron oxides in EMIM TFSI is analyzed on the nanoscale taking care of the NP-IL interface. Always keeping the NPs in a liquid, NPs are transferred from water into pure IL or IL with additives, which allows us to control their initial surface charge and the nature of the associated counterions compensating this charge, thus tuning the ratio $\kappa_{\text {ion }}$. The dispersion state and the structure of the NPs on the nanoscale are first studied at room temperature, associating optical microscopy, dynamic light scattering (DLS) and small angle Xray scattering (SAXS) measurements. In a second step, the optimal systems obtained are examined at high temperature up to $200{ }^{\circ} \mathrm{C}(473 \mathrm{~K})$ combining DLS, SAXS, SANS as well as TGA. As the temperature at which the IL is stable in the long term (hours or months) can be up to a factor two lower than the short-term one from TGA ramps [36, 38], we performed isothermal TGA over hours and DLS measurements over days to determine suitability for applications.

\section{Materials and Methods}

\subsection{Preparation of ionic liquid-based colloids}

The products were purchased and used as received. They are listed in the ESI (S1). The same batch of maghemite $\left(\gamma-\mathrm{Fe}_{2} \mathrm{O}_{3}\right)$ nanoparticles was used for all experiments. This batch was already used in reference [20], where the NPs' synthesis [39, 40] and the sample characteristics are described in detail. After a size sorting process, the fraction kept has a lognormal size distribution with a median diameter $d_{\mathrm{NP}}=8.7 \mathrm{~nm}$ with a polydispersity index of $\sigma_{d}=0.3$. At the end, the NPs are dispersed in water, their surface charge being positive, compensated by nitrate ions, with a $\mathrm{pH}$ of 1.8 and a volume fraction of $4.4 \mathrm{vol} \%$.

To modify the charge and the counterions in the initial samples in water, sodium hydroxide was added to these disper-

${ }^{3}$ Pyrr1(201)TFSI: (1-Methyl-1-(2-Methoxyethyl) Pyrrolidinium TFSI), Pi1(201) TFSI: (1-(2-Methoxyethyl)-1-Methyl Piperidinium TFSI), N1114 TFSI: (N,N,N-triMethyl-N-Butyl Ammonium TFSI), N112(301) TFSI: (N-Ethyl-N,N-diMethyl- N-(3-Methoxypropyl) Ammonium TFSI), EMIM FSI: (EMIM bis(fluorosulfonyl)imide), EMIM TFO: (EMIM trifluoromethanesulfonate). 
sions at a volume fraction of $1 \mathrm{vol} \%$ till the point of zero charge was reached at $\mathrm{pH} \approx 7$. The free ions were washed off several times with ultra-pure water. The particles could then be charged by protonation of the oxide surface with a strong acid. The charge density of the NPs $\sigma$ increases while decreasing the $\mathrm{pH}$ and it is compensated by the conjugate anion of the acid. The $\mathrm{pH}$ was converted into a charge density according to the results obtained with similar NPs with nitric and perchloric acid [41], under the hypothesis that the surface charge does not depend on the nature of the strong acid used [41]. Concretely, $\mathrm{pH}$ values between 5 and 1.3 correspond to surface charge densities $\sigma$ between 4 and $30 \mu \mathrm{C} \mathrm{cm}^{-2}$ (and the equivalent concentrations of added acids are between 0.0035 and $0.075 \mathrm{~mol} \mathrm{~L}^{-1}$ ). This is the maximal reachable charge as lowering the $\mathrm{pH}$ too much can lead to the dissolution of the NPs.

Figure 1 shows the three possible species that can play the role of counterions of the positive NPs, when using the four strong acids here under. HTFSI and HTFO enable to change the $\Theta^{\max }$ values and the nature of the charged group with $\mathrm{TFSI}^{-}$and $\mathrm{TfO}^{-}$as the possible counterions of the NPs. The two other acids HSBMIM TFSI and HSBMIM TfO are ionic liquids when pure. The deprotonated form is thus composed of the zwitterion $\mathrm{SBMIM}^{ \pm}$and of the anion. The ratio between the two entities is one when adding them as one IL. However, this ratio can be varied by adding first HTFSI or HTfO and then SBMIM $^{ \pm}$(which is a powder). Doing so, the value of the initial charge density $\sigma$ is varied independently of the amount of species of opposite charge and the plan $\sigma$ versus [SBMIM $\left.{ }^{ \pm}\right]$is explored.

Once the composition in water was fixed, an equivalent vol-

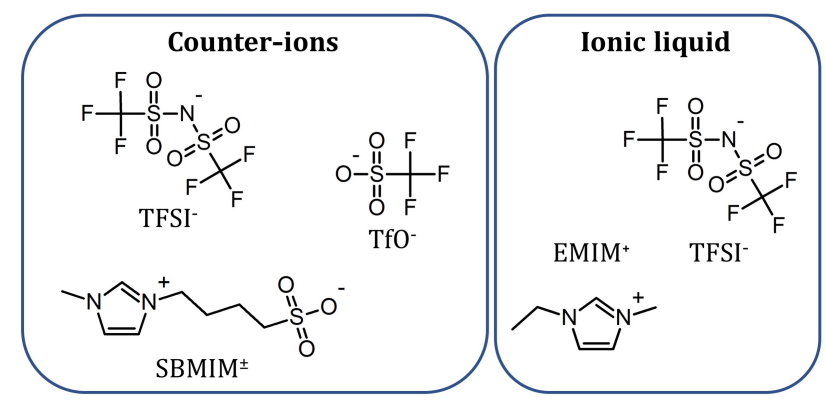

Figure 1: Structures of the ions 1-(4-butylsulfonate)3-methylimidazolium $\quad\left(\mathrm{SBMIM}^{ \pm}\right)$, triflate $\left(\mathrm{TfO}^{-}\right)$, bis(trifluoromethylsulfonyl) amide $\left(\mathrm{TFSI}^{-}\right)$, and 1-ethyl3-methylimidazolium (EMIM $\left.{ }^{+}\right)$.

ume of the EMIM TFSI ionic liquid was added (see Figure 1) and the water was removed by freeze-drying. Therefore the final volume fraction $\Phi_{\mathrm{NP}}$ in the ionic liquid was known (around $1 \mathrm{vol} \%$ ) and the concentrations of the introduced species were also known.

When possible, more concentrated dispersions could be obtained by ultracentrifugation using an Optima 70 device and a type 100 Ti fixed-angle rotor from the company Beckman Coulter, USA. The samples needed to be centrifuged at 55 $000 \mathrm{rpm}(243000 \mathrm{~g})$ for 24 hours at $19{ }^{\circ} \mathrm{C}$. Separating the clear supernatant leaded to concentrated samples with nanoparticle volume fractions $\Phi_{\mathrm{NP}} \approx 10-20 \mathrm{vol} \%$ which could be diluted with their supernatant to appropriate intermediate concentrations.

\subsection{Analyses of the samples}

The ionic liquid-based colloids were analysed by transmission electron microscopy (TEM) using a JEOL-100 CX TEM in order to check that their transfer into the ionic liquid has not changed the shape of the nanoparticles compared to the initial sample in water, i.e there is no dissolution. A droplet of the ionic liquid-based ferrofluids (diluted to around $0.01 \mathrm{vol} \%$ with pure ionic liquid) was deposited on a carbon-coated copper grid and the back-side of the grid was swiped over a paper to remove as much liquid as possible. $^{4}$

Then, on the micron scale, the existence of large agglomerates was checked by optical microscopy. If none were detected, the samples were analyzed by dynamic light scattering (DLS), performed using Vasco, VascoFlex or VascoKin DLS Particle Analyzers from Cordouan Technologies (see ESI section S.2.1. for the technical details). As the viscosity of the ionic liquid-based colloids is difficult to know accurately because it depends on water traces [8] and on the other additives in the dispersions, DLS was mainly used to follow samples in the long term over months. Moreover, as the measurements were performed at $1 \mathrm{vol} \%$ of NPs, only apparent hydrodynamic diameters $d_{\mathrm{H}}$ are given (see details in the ESI sections S2.1. and S3).

At high temperature, DLS was coupled with small angle neutron scattering (SANS) up to $200{ }^{\circ} \mathrm{C}(473 \mathrm{~K})$ for hours. The setup and the details of the experiments performed on the PAXY spectrometer at the LLB facility (CEA Saclay, France) are described in detail in the ESI section S4.1. Three different configurations were used leading to an accessible $Q$ range of $0.005 \AA^{-1}$ to $0.2 \AA^{-1}$.

SAXS experiments were carried out with a laboratory instrument (XEUSS 2.0) in the Q-range $0.0045 \AA^{-1}-0.2 \AA^{-1}$ (see ESI section S.2.2. for details). The SAXS and SANS form factors $P(Q)$ of the nanoparticles were obtained from the extrapolation at $0 \mathrm{vol} \%$ of several dilute colloidal dispersions in water with low interparticle interactions. See the electronic supplementary information (ESI) of [20] for details and the corresponding curves. These form factors were used to determine structure factors $S(Q)$ from the measured intensity $I(Q)$ using:

$$
S(Q)=\frac{I(Q)}{\Delta \rho^{2} V_{\mathrm{NP}} \Phi_{\mathrm{NP}} P(Q)}
$$

where $\Delta \rho^{2}$ is the contrast and $V_{\mathrm{NP}}$ an average volume of the NP and $\Phi_{\mathrm{NP}}$ is the nanoparticle volume fractions determined from flame atomic absorption spectroscopy (FAAS) measurements (see ESI S.2.3.).

\footnotetext{
${ }^{4}$ Note that TEM can not give a reliable insight on the dispersion state of NPs in solution because the preparation of the sample for the TEM measurements can affect the sample's nanostructure due to dilution and exposure to the humidity of the air.
} 
The value of $S(Q \rightarrow 0)$ therefore compares the studied dispersions to a "reference" dispersion of individual nanoparticles without interparticle interaction. The difference can be due to interparticle interaction or to a change of the volume/form of the scattering objects (for example formation of small aggregates).

Isothermal and ramped temperature thermogravimetric analysis (TGA) were performed with a TGA 550 from TA Instruments (see details in ESI, S4.2.).

\section{Results and discussion}

\subsection{Analysis of the dilute samples at 1 vol\% at room temperature}

Using the four strong acids to change the surface charge and $\mathrm{SBMIM}^{ \pm}$to modify the surface, the $\sigma-\left[\mathrm{SBMIM}^{ \pm}\right]$plane, where $\sigma$ is the initial surface charge density in water, can be explored to outline stability behaviors (see Figure 2). In these diagrams, the special case of the ratio SBMIM $^{ \pm}$/ $\mathrm{TFSI}^{-}$or $\mathrm{TfO}^{-}$equal to one (easily reached when adding directly HSBMIM TFSI or HSBMIM TfO ILs) is shown with the brown line. Here, the quality of the dispersions in the IL is addressed with DLS measurements. These diagrams evidence that:

1) With $\mathrm{TFSI}^{-}$or $\mathrm{TfO}^{-}$counterions and $\left[\mathrm{SBMIM}^{ \pm}\right]=0$, the NPs are floculated whatever the surface charge densities (from 4 to $30 \mu \mathrm{C} \mathrm{cm}^{-2}$ ). This corresponds to the $y$-axis in Figure 2.

2) Adding $\mathrm{SBMIM}^{ \pm}$to these systems can stabilize the nanoparticles if the surface charge density is high enough, which means that some $\mathrm{SBMIM}^{ \pm}$localises at the solid liquid interface.

3) For a given amount of $\mathrm{SBMIM}^{ \pm}$and for a given acid, the apparent hydrodynamic diameter $d_{\mathrm{H}}$ decreases while the surface charge density $\sigma$ increases, when dispersions are obtained.

4) For a given charge density $\sigma, d_{\mathrm{H}}$ depends on $\left[\mathrm{SBMIM}^{ \pm}\right]$ and there is an optimal concentration for the minimal $d_{\mathrm{H}}$. SAXS confirms that there is a change in the nanostructure while changing the concentration of $\mathrm{SBMIM}^{ \pm}$for a given charge (see section S3 in ESI, Figure S2).

5) The final dispersion state in EMIM TFSI in the presence of SBMIM $^{ \pm}$depends on the initial counterion introduced, i.e. $\mathrm{TFSI}^{-}$or $\mathrm{TfO}^{-}$. For example for a surface charge density of $14 \mu \mathrm{C} \mathrm{cm}^{-2}\left(0.014 \mathrm{~mol} \mathrm{~L}^{-1} \mathrm{TfO}^{-}\right.$or TFSI ${ }^{-}$introduced with the added acid) and a $\mathrm{SBMIM}^{ \pm}$concentration in the range $0.07-0.1 \mathrm{~mol} \mathrm{~L}^{-1}$, the apparent hydrodynamic diameter for nanoparticle dispersions containing $\mathrm{TfO}^{-}$is around $70 \mathrm{~nm}$, although it is bigger than $100 \mathrm{~nm}$ for dispersions with TFSI $^{-}$.

The best dispersions states are obtained in the green areas of the diagrams (Figure 2). They correspond to the smallest $\mathrm{d}_{H}$ and lowest $\mathrm{S}(0)$, i.e. the lowest NP size and/or the maximal repulsive interparticle interaction. The optimal ones correspond to the maximal charge density $\sigma \approx 30 \mu \mathrm{C} \mathrm{cm}^{-2}$. Among the intermediate $\mathrm{SBMIM}^{ \pm}$concentrations in the green area, $\left[\mathrm{SBMIM}^{ \pm}\right]=0.075 \mathrm{~mol} \mathrm{~L}^{-1}$ is among the opti-
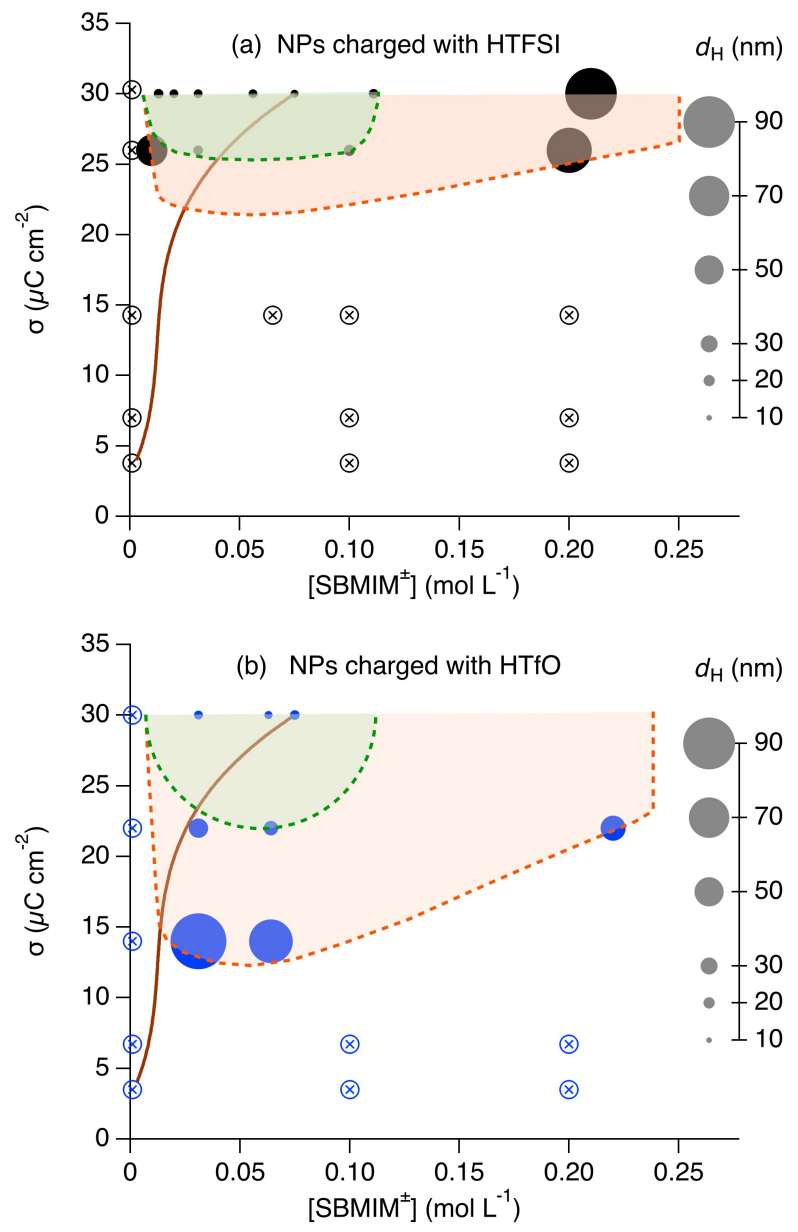

Figure 2: Diagrams of the different nanostructures obtained in the dispersions of NPs in EMIM TFSI. The $X-Y$ plane explored is the added concentration of $\operatorname{SBMIM}^{ \pm}(X)$ and the initial charge density of the NPs in water $\sigma(\mathrm{Y})$. The symbols $\otimes$ correspond to aggregated samples. When DLS can be performed, the surface of the disks is proportional to the apparent size extracted from DLS $\mathrm{d}_{H}$ (scale on the right). (a) $\sigma$ increased by adding HTFSI; (b) $\sigma$ increased by adding HTFO. The (calculated) brown line corresponds to $\left[\mathrm{SBMIM}^{ \pm}\right]=[\mathrm{HTFSI}]$ or [HTFO]. The green area indicates the region where the best samples are obtained (lowest $d_{H}$ ). The red area indicates the region where samples are dispersed however with aggregates up to $90 \mathrm{~nm}$.

mal values, as confirmed by SAXS (see section S3 in ESI). This corresponds to a ratio $\mathrm{SBMIM}^{ \pm}$to $\mathrm{TFSI}^{-}$or $\mathrm{SBMIM}^{ \pm}$ to $\mathrm{TfO}^{-}$of 1 . It is thus easily reached by directly adding HSBMIM TFSI or HSBMIM TfO. SAXS also proves that several independent preparations with this composition are very reproducible (see section S3 in ESI, Figure S2).

\subsection{The most stable samples: detailed nanostructure at room temperature, 1 vol $\%$}

The most stable dispersions obtained from the diagrams of Figure 2 are analyzed in details comparing the two systems (i) HSBMIM TFSI, where the anionic species are TFSI ${ }^{-}$ and the sulfonate group of $\mathrm{SBMIM}^{ \pm}$; (ii) HSBMIM TfO, 
where the anionic species are $\mathrm{TFSI}^{-}, \mathrm{TfO}^{-}$and the sulfonate group of $\mathrm{SBMIM}^{ \pm}$(the molecules are shown in Figure 1). The images from transmission electron microscopy (TEM,

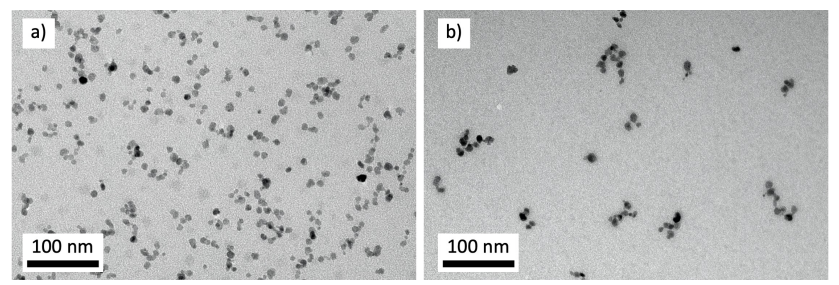

Figure 3: TEM images of nanoparticles dispersed in the ionic liquid EMIM TFSI with a) $\left[\mathrm{SBMIM}^{ \pm}\right]=0.075 \mathrm{~mol} \mathrm{~L}^{-1}$ and $\mathrm{b}$ ) $\left[\mathrm{SBMIM}^{ \pm}\right]=\left[\mathrm{TfO}^{-}\right]=0.075 \mathrm{~mol} \mathrm{~L}^{-1}$. The ion structures are depicted in Figure 1. Both samples were diluted to a nanoparticle volume fraction $\Phi_{\mathrm{NP}} \approx 0.01$ vol\% with pure EMIM TFSI before the deposition of the ionic liquid-based colloid on the TEM grid.

Figure 3) show for both systems that the shape of the nanoparticles is not changed compared to the initial sample in water (TEM picture given in ref [20]). Moreover, the nanoparticles do not appear organized in the same way using HSBMIM TFSI or HSBMIM TfO: loose clusters are observed with HSBMIM TfO although the NPs seem more homogeneously dispersed with HSBMIM TFSI. However no definite conclusion can be extracted from the TEM images due to the perturbations induced by the measurement (see section 2.2). Figure 4 plots the scattered intensity I(Q) by SAXS for these two samples and the reference form factor for comparison, at room temperature after the preparation and one year later. Figure 5 plots the structure factors $S(Q)$ from SANS for these two samples (red curves). If $\mathrm{I}(\mathrm{Q} \rightarrow 0) / \Phi$ is larger than $\mathrm{I}$ (form factor), i.e. if $S(Q \rightarrow 0)>1$, the interparticle interaction is attractive. If $\mathrm{I}(\mathrm{Q} \rightarrow 0) / \Phi$ is lower than $\mathrm{I}$ (form factor), i.e. if $\mathrm{S}(\mathrm{Q} \rightarrow 0)<1$, the interparticle interaction is repulsive.

From both SAXS and SANS it can be deduced that the global interparticle interactions of the system with HSBMIM TfO is attractive $(\mathrm{S}(\mathrm{Q} \rightarrow 0)>1)$ and that of the system with HSBMIM TFSI is repulsive $(\mathrm{S}(\mathrm{Q} \rightarrow 0)<1)$. This shows that not only the zwitterion $\mathrm{SBMIM}^{ \pm}$stabilises the nanoparticles but that introducing the additional anions $\mathrm{TfO}^{-}$, although with a low concentration $\left(0.075 \mathrm{~mol} \mathrm{~L}^{-1}\right)$ modifies the organisation of the molecules close to the NPs, and therefore the organisation of the NPs. Moreover, both dispersions are stable in the long run as the scattering intensity after one year is similar to the initial one (Figure 4).

$S(Q \rightarrow 0)$ is related to the osmotic pressure $\Pi$ by

$$
S(Q \rightarrow 0)=\frac{k T}{V_{N P}} \frac{\partial \Phi_{\mathrm{NP}}}{\partial \Pi}
$$

with $V_{\mathrm{NP}}$ the average volume of a nanoparticle. At a low volume fraction $\Phi_{\mathrm{NP}}$, the virial expansion of $\Pi$ relates $\mathrm{S}(\mathrm{Q} \rightarrow 0)$ to the second order virial coefficient $A_{2}$ by:

$$
S(Q \rightarrow 0) \simeq \frac{1}{1+2 A_{2} \Phi_{\mathrm{NP}}}
$$

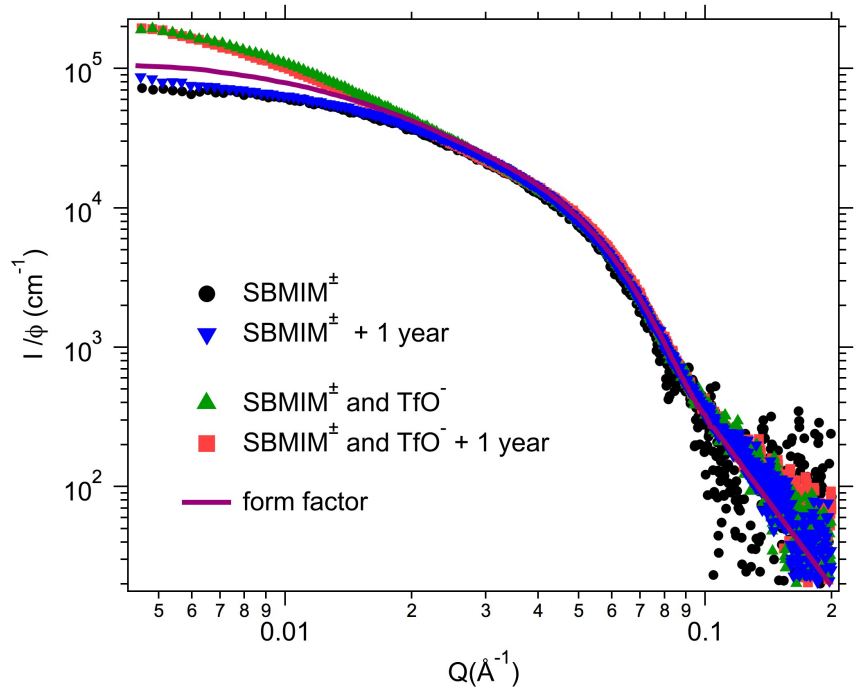

Figure 4: Absolute scattered intensities (normalized by the nanoparticle volume fraction $\Phi_{\mathrm{NP}} \approx 1 \mathrm{vol} \%$ ) as a function of $\mathrm{Q}$ obtained by SAXS for dispersions of nanoparticles in EMIM TFSI one year apart. Sample with $\left[\mathrm{SBMIM}^{ \pm}\right]=0.075 \mathrm{~mol} \mathrm{~L}^{-1}$ was stored in contact with (the moisture of) air. Sample with $\left[\mathrm{SBMIM}^{ \pm}\right]=\left[\mathrm{TfO}^{-}\right]=0.075 \mathrm{~mol} \mathrm{~L}^{-1}$ was stored under dry atmosphere.

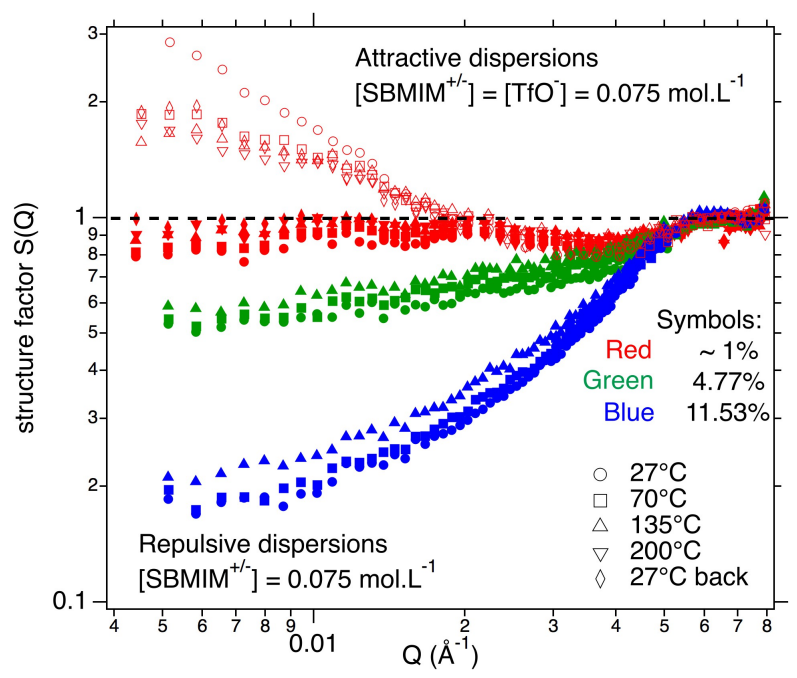

Figure 5: Structure factors $S(Q)$ obtained by small angle neutron scattering (SANS) as a function of the scattering vector $Q$ for nanoparticle dispersions in EMIM TFSI. The symbols and colors are explained in the legends. Attractive dispersions with $\left[\mathrm{SBMIM}^{ \pm}\right]=\left[\mathrm{TfO}^{-}\right]=0.075 \mathrm{~mol} \mathrm{~L}^{-1}$, (empty red symbols). Note that the data at $27{ }^{\circ} \mathrm{C}$ before the heating cycle (empty red circles) are an experimental artifact, not observed with SAXS (see Figure 6). This is attributed to some pollution reversibly removed while heating. Repulsive dispersions with $\left[\mathrm{SBMIM}^{ \pm}\right]=0.075 \mathrm{~mol} \mathrm{~L}^{-1}$ (full symbols): Note that there is no SANS at $200{ }^{\circ} \mathrm{C}$ for both concentrated samples due to leaks of the cells (SAXS and DLS with the remaining sample are shown in Figure 6).

With measurements at $\Phi_{\mathrm{NP}}=1$ vol\% only, and even with the required condition $2 A_{2} \Phi_{\mathrm{NP}} \ll 1$ not fulfilled, we tentatively 
give here an evaluation of $A_{2}$ (at least its sign is correct). We obtain $A_{2} \simeq-23$ for the attractive system and $A_{2} \simeq 13$ for the repulsive one.

These results are consistent with the DLS measurements. For the repulsive dispersion with HSBMIM TFSI, $d_{\mathrm{H}}$ is approximately $12 \mathrm{~nm}$ (as for the initial water samples [20]), which proves that no aggregates are present. For the attractive dispersion with HSBMIM TfO, $d_{\mathrm{H}} \approx 25 \mathrm{~nm}$, which indicates the presence of small aggregates in the order of a few particles per aggregate.

\subsection{Increasing the nanoparticles volume fraction at room temperature}

Only the system made with HSBMIM TFSI could be largely concentrated as it is repulsive. Indeed, attractive ionic liquid-based colloids lead to a phase separation when increasing the volume fraction, as observed for citrated iron oxide NPs of similar size with various counterions in another IL [42].

The interparticle interactions were analyzed by SAXS and SANS measurements as a function of the nanoparticle volume fraction $\Phi_{\mathrm{NP}}$. The structure factors from SANS are plotted in Figure 5. The deduced values of $S(Q \rightarrow 0)$ by SAXS and SANS are shown in Figure 6. For a repulsive system, at a volume fraction $\Phi_{\mathrm{NP}}, S(Q \rightarrow 0)$ equals the osmotic compressibility $\chi\left(\Phi_{\mathrm{NP}}\right)$, which decreases with increasing $\Phi_{\mathrm{NP}}$. In this case, the Carnahan-Starling expression for effective hard spheres $[43,44]$ can be used to analyze the compressibility $\chi$ up to large volume fractions as in references $[25,45$, $46,47,48,49,50]$. Equation (4) describes the compressibility

$$
\chi\left(\Phi_{\mathrm{NP}}\right)=\chi_{\mathrm{CS}}\left(\Phi_{\mathrm{eff}}\right)=\frac{\left(1-\Phi_{\mathrm{eff}}\right)^{4}}{1+4 \Phi_{\mathrm{eff}}+4 \Phi_{\mathrm{eff}}^{2}-4 \Phi_{\mathrm{eff}}^{3}+\Phi_{\mathrm{eff}}^{4}}
$$

with

$$
\Phi_{\mathrm{eff}}=\Phi_{\mathrm{NP}} \frac{d_{\mathrm{eff}}^{3}}{d_{\mathrm{NP}}^{3}}=\Phi_{\mathrm{NP}}\left(1+\frac{2 \kappa^{-1}}{d_{\mathrm{NP}}}\right)^{3}
$$

and

$$
d_{\mathrm{eff}}=d_{\mathrm{NP}}+2 \kappa^{-1}
$$

In this model, an effective Hard Sphere, the radius of which is increased by a characteristic length $\kappa^{-1}$, accounts for the spatially decreasing interparticle interaction potential due to the ionic organization around the NPs (as the one produced by organized ions around NPs in polar solvents). The twobodies interparticle interaction $\mathrm{A}_{2}$ is then

$$
A_{2}=4 \frac{\Phi_{\mathrm{eff}}}{\Phi_{\mathrm{NP}}}
$$

The experimental data of the compressibility are fitted in Figure 6 with the Equations (4) and (5). The best fit is obtained for a fitting parameter $\kappa^{-1} \approx 1.0 \mathrm{~nm}$ taking the TEM median diameter $d_{\mathrm{NP}}=8.7 \mathrm{~nm}$. This characteristic length is much smaller than the long-range interaction length frequently observed in IL by force measurements between charged surfaces [30]. It is related here to the organization of the ionic liquid layers localized close to the NPs. The extension of these layers is larger than $\kappa^{-1}$. Approximating the effective Hard Sphere potential by a decreasing exponential of characteristic length $\kappa^{-1}$, it would roughly extend up to 3-5 $\kappa^{-1}$ hence over 3-5 nm. The two-bodies interparticle interaction $A_{2}{ }^{5}$ is then $A_{2}=7.3 \pm 0.5$ which is almost the double of the hard sphere value $A_{2}^{\mathrm{HS}}=4$ [43] and of the values obtained for citrate-coated oxide nanoparticles in ethylammonium nitrate with sodium counterions and smaller NPs $\left(A_{2}=4.6\right)[19,25]$.

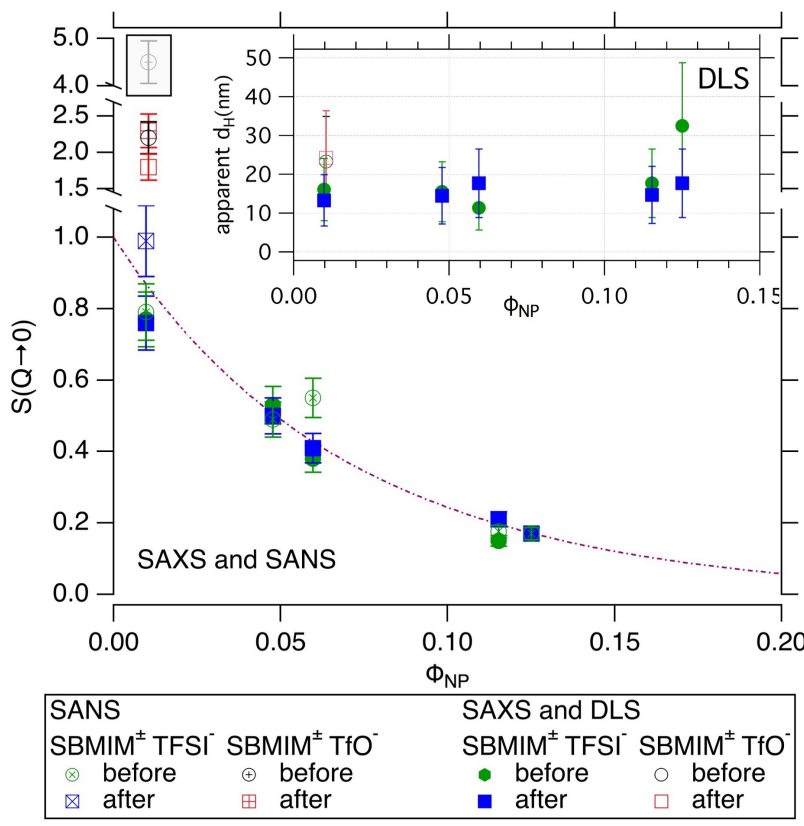

Figure 6: $\mathrm{S}(\mathrm{Q} \rightarrow 0)$ deduced from SAXS and SANS (data of Figure 5) measurements at room temperature for the repulsive system $\left(\left[\mathrm{SBMIM}^{ \pm}\right]=0.075 \mathrm{~mol} \mathrm{~L}^{-1}\right)$ as a function of the nanoparticle volume fraction $\Phi_{\mathrm{NP}}$ and for the attractive system $\left(\left[\mathrm{SBMIM}^{ \pm}\right]=\left[\mathrm{TfO}^{-}\right]=0.075 \mathrm{~mol} \mathrm{~L}^{-1}\right)$ at $\Phi_{\mathrm{NP}}=1.04 \mathrm{vol} \%$. The dashed-dotted line corresponds to the fit of the data for the repulsive samples with Equations (4) and (5) using $\Phi_{\text {eff }} / \Phi_{\mathrm{NP}}=1.82$ (two-bodies interparticle interaction quantified by the second virial coefficient $A_{2}=7.3 \pm 0.5$ ). Inset: apparent hydrodynamic diameter $d_{\mathrm{H}}$ as a function of the nanoparticle volume fraction $\Phi_{\mathrm{NP}}$ for both systems. The data in the grey box is an artifact (see Figure 5). Both room temperature data before and after heating the samples for several hours up to $200{ }^{\circ} \mathrm{C}(473 \mathrm{~K})$ are shown.

\footnotetext{
${ }^{5}$ Note that using Equation $7, A_{2}$ is directly obtained from the adjustment parameter $\Phi_{\text {eff }} / \Phi_{\mathrm{NP}}$, which is independent of the $d_{\mathrm{N} P}$ value used to deduce $\kappa^{-1}$ in Equation 5
} 


\subsection{Thermal stability of the most stable dispersions}

The knowledge of the dispersions' behavior while heating is essential for the evaluation of the possible applications of such fluids. The two optimized systems are analyzed in details coupling several techniques on different scales: SANS and DLS up to $200{ }^{\circ} \mathrm{C}(473 \mathrm{~K})$ and additional DLS and SAXS measurements before and after heating periods. Complementary TGA analyses are also presented, which brings an indirect and global information while heating.

\subsubsection{Nanostructure}

Given the limited allocated SANS beamtime, few temperatures were chosen $\left(27{ }^{\circ} \mathrm{C}, 70{ }^{\circ} \mathrm{C}, 135^{\circ} \mathrm{C}, 200{ }^{\circ} \mathrm{C}\right.$, and back at $27{ }^{\circ} \mathrm{C}$ ) for the in-situ measurements of SANS and DLS up to $200^{\circ} \mathrm{C}$. For each step, DLS was performed after heating and enables checking that equilibrium is reached before measuring SANS. This is possible as the viscosity varies with temperature which influences the correlation function. Hence, stability of the correlation function means that viscosity and temperature are stable. DLS performed after SANS tells us whether some change occurred. One $T$ step lasts around two hours, the whole cycle from $27^{\circ} \mathrm{C}$ back to $27^{\circ} \mathrm{C}$ around 10 hours. Such DLS data are presented in ESI, section S4.1, Figure S4. The SANS structure factors are plotted in Figure 5 and their extrapolation to $Q=0$ in the Figure S5 in ESI. The structure factor at $Q=0$ (from both SANS and SAXS) and the apparent $d_{\mathrm{H}}$ (from DLS) are plotted respectively in the main graph and the inset of Figure 6 before and after heating.

Looking first at the two samples at $\Phi_{\mathrm{NP}} \approx 1$ vol\% with different interfacial species, they show a weak evolution after they stay at high temperature. Indeed, the strong initial decrease of intensity for the attractive dispersions from $27{ }^{\circ} \mathrm{C}$ to $70{ }^{\circ} \mathrm{C}$ appears as an experimental artifact. The corresponding SAXS measurement at room temperature gives $\mathrm{S}(\mathrm{Q} \rightarrow 0)=2.2 \pm 0.2$, which matches with the SANS after the cycle. Moreover, the DLS is similar before and after heating. This artifact can be due to some pollution (water, solvent,...) that is removed while heating. Leaving aside this point, the values of $S(Q \rightarrow 0)$ show that for this attractive sample, the same small aggregates/weak attractions remain whatever the temperature. Both the repulsive and the attractive sample appear stable on the time scale of the experiment. For the repulsive dispersions, the interaction remains repulsive whatever the temperature. However, given the small increase of $S(Q \rightarrow 0)$ at $\Phi_{\mathrm{NP}}=0.97$ vol\% from $0.83 \pm 0.08$ to $0.98 \pm 0.10$ after heating, close to the error bar, a longterm experiment was performed. The sample was heated in a glass tube for several days at three temperatures up to $170{ }^{\circ} \mathrm{C}$ under vacuum and its state was checked with a DLS measurement at room temperature after each plateau. The results are summarized in Figure 7. The apparent hydrodynamic diameter is $d_{\mathrm{H}}=12 \pm 2 \mathrm{~nm}$ showing that the sample is long-term stable at high temperature, here during 18 days. The analysis of the concentrated repulsive samples by SANS, SAXS and DLS shows that the structure factors are close to

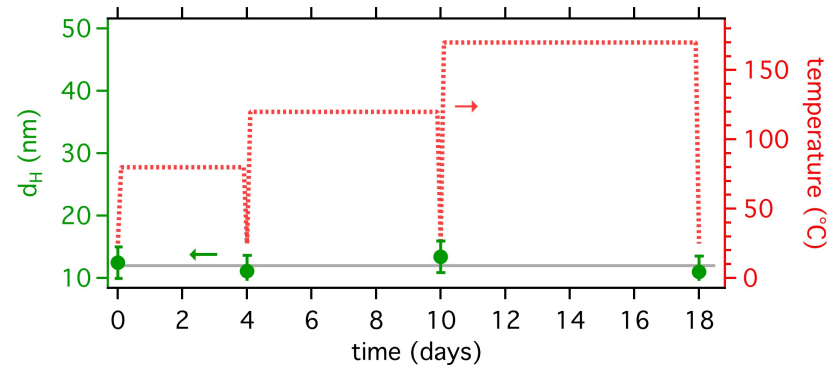

Figure 7: DLS measurements at room temperature for the repulsive dispersions at $\Phi_{\mathrm{NP}}=0.97$ vol\% shown in Figure 5 and 6 (green circles). The sample was previously heated in a low vacuum around 10 mbar in an open bottle at the indicated temperatures for days (red dotted lines). Note that the maximum temperature of the heating device is $170{ }^{\circ} \mathrm{C}$. These DLS measurements at room temperature give extra information about temperature cycling.

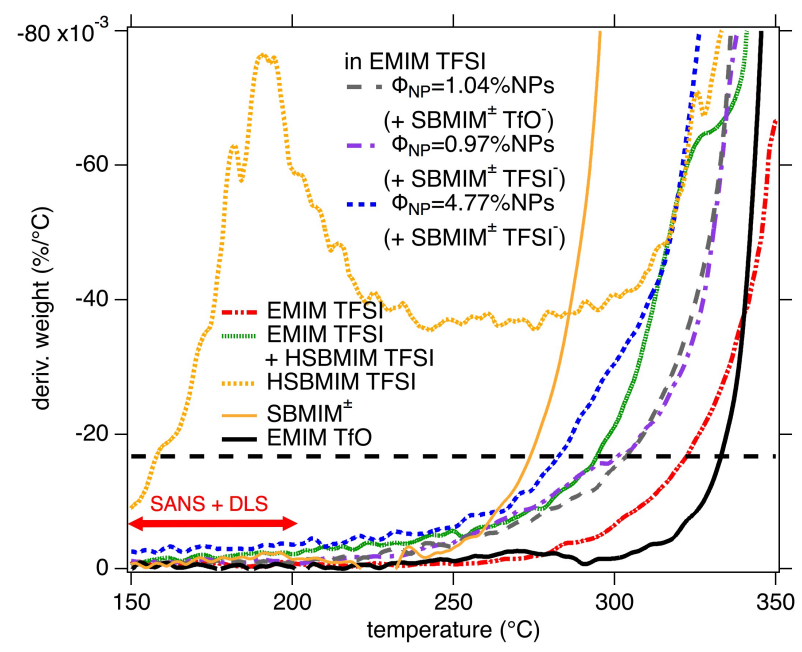

Figure 8: Ramped thermogravimetric analysis (TGA) measurements for the resulting dispersions in EMIM TFSI and for the components of these dispersions. Attractive and repulsive dispersions with $\Phi_{\mathrm{NP}} \simeq 1$ vol\%, repulsive dispersions with $\Phi_{\mathrm{NP}}=4.77 \mathrm{vol} \%$. EMIM TFSI and EMIM TfO without NPs were wet to mimic the worst amount of water that could remain in the dispersions. Dry SBMIM $^{ \pm}$and dry EMIM TFSI containing $2.5 \mathrm{wt} \%$ HSBMIM TFSI (amount present in the dispersions at $1 \mathrm{vol} \%$ ) are also depicted. $T_{\text {start }}$ (weight loss of $10 \%$ per hour here) is indicated in the graph by the horizontal black dashed line. All the measurements were performed in $\mathrm{Pt}$ pans except HSBMIM TFSI for which an alumina crucible was used (see Figure S6 in ESI for more details).

those at room temperature and the compressibilities $\mathrm{S}(\mathrm{Q} \rightarrow 0)$ before and after heating are also quite similar (Figure 5 for SANS and Figure 6 for $\mathrm{S}(\mathrm{Q} \rightarrow 0)$ ). The apparent $d_{\mathrm{H}}$ differ before and after heating for the concentrated samples (Figure 6 , inset), with no systematic trend. We therefore attribute the variations to the difficulties of measurement of the concentrated samples in the furnace, which leads to large error bars.

All these elements converge towards the conclusion that the 
stability of these concentrated samples at high temperature is good, and that the same nanostructure and interaction are kept.

\subsubsection{Thermogravimetric analyses}

Such an analysis can be performed in different ways, the most classical being temperature heating ramps. However they correspond to short measurements and can overestimate the decomposition temperature. This is why other types of measurements as isothermal ones over hours or longer times were also done here.

In a first step, heating ramps up to $600{ }^{\circ} \mathrm{C}(873 \mathrm{~K})$ have been acquired for ILs without and with NPs. We will focus here on $T_{\text {start }}$ (see caption of Figure 8), the temperature at which the sample starts to loose weight, which appears to be more relevant here than the most used $T_{\text {onset }}$ (see ESI, section S4.2.). The raw data are shown in the ESI (Figure S6, section S4.2.), as well as the details on usual and used definitions, and the large table $\mathrm{S} 1$ gathers our values experimentally determined and values from literature. Note that $T_{\text {start }}$ and long-term behaviors are scarce in literature, except for pure EMIM TFSI and EMIM TfO to a lesser extent. The derivative mass losses are plotted in Figure 8.

For the dispersions at $\Phi_{\mathrm{NP}} \approx 1$ vol\%, both attractive and repulsive, $T_{\text {start }}$ equals $303^{\circ} \mathrm{C}$ and is lowered by $20^{\circ} \mathrm{C}$ for the repulsive sample at $4.77 \mathrm{vol} \%$. This can be compared with the pure ILs, however the dispersions contain several species that should all be considered. For the pure EMIM TFSI, $T_{\text {start }}=320{ }^{\circ} \mathrm{C}$ [36], a little higher than that for the $1 \mathrm{vol} \%$ dispersions. In the sample, a maximum of one or two water layers may stay close to the NPs' interface, which would correspond to $0.1-0.2 \mathrm{wt} \%$. Therefore EMIM TFSI saturated with water at room temperature was measured, which corresponds to $0.5 \mathrm{wt} \%$, a higher value nevertheless in the same range. Its $T_{\text {start }}$ is close to the value from literature although $T_{\text {onset }}$ is reduced by a few tens of degrees (ESI table S1). The other species present in the sample are $\mathrm{SBMIM}^{ \pm}$, the zwitterion that is at the interface and possibly some HSBMIM. $T_{\text {start }}\left(\mathrm{SBMIM}^{ \pm}\right)=274^{\circ} \mathrm{C}$, which is still high. Pure HSBMIM TFSI appears to be the less stable species, that has to be measured in alumina crucibles as it seems to decompose in Pt pans close to room temperature (see Figure S7 in ESI, section S4.2. $)^{6}$. $T_{\text {start }}($ HSBMIM TFSI $)=158{ }^{\circ} \mathrm{C}$, which cannot be compared with literature as no data were found on this liquid. Only $T_{\text {onset }}$ of IL of the same family (sulfoimidazolium) could be found [51, 52], showing values close to our results on HSBMIM TFSI (see table S1 in ESI). The last species, present in the attractive sample only, is $\mathrm{TfO}^{-}$anions, the stability of which can be evaluated from EMIM TfO. Despite a high $T_{\text {onset }}=348^{\circ} \mathrm{C}$, the temperature at which $1 \%$ is lost after one year is $185^{\circ} \mathrm{C}$, much lower than for EMIM TFSI $\left(286^{\circ} \mathrm{C}\right)$ [53].

Finally, it appears important to mention that partial evaporation of the sample also leads to a weight loss although

\footnotetext{
${ }^{6}$ Note that using alumina crucibles for the other samples shifts the curves, which keep their shape (see Figure S7 in ESI). As these data are only used for comparisons of samples, only data with Pt pans are kept for all samples except HSBMIM TFSI.
}

the sample is not decomposed. For example, EMIM TFSI is considered relatively volatile compared to other ionic liquids and its partial pressure at $200{ }^{\circ} \mathrm{C}$ is $0.02 \mathrm{~Pa}$ (calculated with the values of ref [53]), around a magnitude larger than for EMIM TfO. Note that the long-term stabilities after one year mentioned in the previous paragraph are corrected from the losses due to evaporation (see Table S1 in ESI).

In a second step, isothermal TGA measurements at $200{ }^{\circ} \mathrm{C}$ during $15 \mathrm{~h}$ are performed on the repulsive samples to estimate their stability at this temperature (see Figure S8 of the ESI). The first analysis in classical Pt crucibles shows that the weight loss for the ionic liquid EMIM TfO is smaller than $0.1 \%$ after 15 hours at $200^{\circ} \mathrm{C}$. For EMIM TFSI, the weight loss is a bit higher $(0.2 \%)$ and increases with the NPs volume fraction up to $1.5 \mathrm{vol} \%$. The latter measurements reproduced in alumina crucible where the interference between HSBMIM and platinum is eliminated and the evaporation limited show a weight variation lower than $0.2 \mathrm{wt} \%$ after 15 hours for both the solvent and the dispersions, pointing towards a good stability of these repulsive dispersions at our maximal temperature of study of the nanostructure.

\subsection{Discussion}

Among the performed tests, four different types of interfaces are explored, each one in a specific range of NPs' charge and concentrations of the species that can localize at the interface. We discuss the differences of stability observed first at room temperature, then at temperature up to $200{ }^{\circ} \mathrm{C}(473 \mathrm{~K})$.

\subsubsection{Room temperature}

The four systems explore four different types of interfaces chosen to vary the ratio $\kappa_{\text {ion }}=\left|\sigma / \Theta_{\text {ion }}^{\max }\right| . \sigma$ is the solid's surface charge density and $\Theta_{\text {ion }}^{\max }$ the maximum charge density of a densely packed counterion monolayer [23]. It was shown by MD simulations on flat surfaces of variable charge in the presence of one ionic liquid (one type of anion, one type of cation) that this ratio governs the organization close to the solid surface. A multilayered structure of positive and negative ions forms at the solid surface, the extention of which is maximal around $\kappa_{\text {ion }} \simeq 0.5[23,54]$. In the present systems, the initial density of charge $\sigma$ in water can be varied through the acidity of the surrounding medium. Assuming a similar behaviour for the nanoparticle charge $\sigma$ with the different counterions [41], $\sigma$ is here tuned between 4 and $30 \mu \mathrm{C} \mathrm{cm}^{-2}$. We assume that this charge is kept in the EMIM TFSI after transfer. $\Theta_{\text {ion }}^{\max }$ is varied through the nature, thus the size, of the ions. Here the particles are positively charged, therefore the compensating ions are the anions. $\left|\Theta_{\mathrm{TFSI}^{-}}^{\max }\right| \approx 50 \mu \mathrm{C} \mathrm{cm}^{-2}[55],\left|\Theta_{\mathrm{TfO}^{-}}^{\max }\right| \approx 100 \mu \mathrm{C} \mathrm{cm}^{-2}$ assuming that $\mathrm{TfO}^{-}$is around half the size of the $\mathrm{TFSI}^{-}$anion, and $\left|\Theta_{\mathrm{SBMIM}^{ \pm}}^{\max }\right| \approx 35 \mu \mathrm{C} \mathrm{cm}^{-2}$ considering that $\mathrm{SBMIM}^{ \pm}$ is a BMIM $^{+}$cation with an extra sulfonate group leading to a slightly smaller $\Theta_{\text {ion }}^{\max }$ value. By way of comparison, $\left|\Theta_{\text {EMIM }^{+}}^{\max }\right| \approx 45 \mu \mathrm{C} \mathrm{cm}^{-2}$.

In the first system, the positive NPs are in EMIM TFSI, 
and the $\mathrm{TFSI}^{-}$anion is the only anionic species. Whatever the ratio $\kappa_{\text {ion }}$ (from 0.08 to 0.6 ), a stable dispersion is never obtained. It means that the best ionic organization is not sufficient to counterbalance the attractive interactions.

In the second system, the positive NPs are still in EMIM TFSI however $\mathrm{TfO}^{-}$anions are introduced while charging the NPs (adding HTfO). Their amount thus equals the number of charges of the NPs plus the amount associated with the free acid in the surrounding liquid. As sulfonate groups have a good affinity for the iron oxide surface [56], $\kappa_{\text {ion }}$ is expected to be lower than for the first system, i.e. between 0.3 for an interface covered by $\mathrm{TfO}^{-}$and 0.6 with no $\mathrm{TfO}^{-}$present. It nevertheless does not lead to stable dispersions. Note that the same NPs in EMIM TfO, therefore with only $\mathrm{TfO}^{-}$anions located at the NPs' interface ( $\kappa_{\text {ion }} \simeq 0.3$ ), are also flocculated.

In the third system, a zwitterion is introduced, $\mathrm{SBMIM}^{ \pm}$. Its anionic group is a sulfonate, with a good affinity for iron oxide. Its cationic group is an imidazolium as the cationic group of the ionic liquid, EMIM TFSI. As summarized in the diagrams in Figures 2 and S2, there are thresholds of $\sigma$ and $\left[\mathrm{SBMIM}^{ \pm}\right]$above which dispersions exist, the quality of which varies a lot. The introduction of this zwitterion thus deeply modifies the interface, even at low concentrations and can lead to stable dispersions. The best dispersions (lower $d_{\mathrm{H}}$ and lower $\left.S(0)\right)$ are obtained for the highest charge density. However, NPs can be dispersed before a monolayer of SBMIM $^{ \pm}$covers the surface with a full layer of molecules perpendicular to the surface (around $0.02 \mathrm{~mol} \mathrm{~L}^{-1}$ ). It means that either the zwitterions are tilted or that mixed layers with $\mathrm{TFSI}^{-}$are formed. The analysis by SAXS shows that the lowest $S(0)(<1$, thus indicating the most repulsive interaction) are obtained for $\mathrm{SBMIM}^{ \pm}$concentrations corresponding to values higher than a monolayer (within the hypothesis that all molecules are located at the interface). According to the estimation of $\Theta_{\text {ion }}^{\max }$, a monolayer of $\mathrm{SBMIM}^{ \pm}$at the maximal $\sigma$ corresponds to $\kappa_{\text {ion }}$ close to 1 . Such a monolayer then shifts the positive charge of the NPs facing the IL by the length of the SBMIM molecule $(8-10 \AA)$ and adds a steric repulsive contribution to the interparticle interaction. The TFSI ${ }^{-}$anions and the IL can then organize on top of $\mathrm{SBMIM}^{ \pm}$layer. In this case, the extent of the organization produces a sufficient repulsion and long-term stable (years) samples with a repulsive interparticle interaction that remain constant over time. Figure 9a shows a possible organization of the solid-liquid interface. Such an organization with few alternate layers of ions is several nanometers thick, which is compatible with the effective range determined from SANS/SAXS in section 3.3.

The fourth system is similar to the third one, however an amount of $\mathrm{TfO}^{-}$anions equal to the number of $\mathrm{SBMIM}^{ \pm}$ zwitterions is introduced in the system. The trends are similar with $\sigma$ and $\mathrm{SBMIM}^{ \pm}$, however this small $\mathrm{TfO}^{-}$amount has dramatic effects: no repulsive systems are obtained with the explored parameters. There is always a weak attractive interaction, constant over time. This proves that the interface differs from the one in the third system. Now two sulfonate groups can compete at the iron oxide's interface: $\mathrm{TfO}^{-}$and $\mathrm{SBMIM}^{ \pm}$, the former being much smaller then the latter. This will modify the first layer, which can no longer be considered as a simple shift of the NPs' surface, and as a consequence it will also modify the following layers. Figure $9 b$ shows a possible organization of the solid-liquid interface.

\subsubsection{High temperatures: macroscopic analysis up to $200{ }^{\circ} \mathrm{C}$}

The next question is the behavior at high temperature of these stable dispersions obtained at room temperature. Both a microscopic (SANS, SAXS, DLS) and a macroscopic approach (TGA) have been used. The macroscopic approach by TGA raises the question of the criteria chosen and of the extrapolations to long-term behaviors. As already said before, $T_{\text {onset }}$ and less frequently $T_{\text {start }}$ are usually extracted from short-term measurements under gas flow. We choose the latter, as being more relevant for high $T$ stability. On the long-term, several criteria have been defined: one example is a $1 \%$ weight loss in 10 hours $T_{0.01 / 10 \mathrm{~h}}[36]$ and another one is the maximum temperature for an annual decomposition of $1 \% T_{\text {max }, 0.01 / y e a r ~}[57,53]$, a value extrapolated from isothermal measurements on much shorter duration than 1 year. All these values are available here only for EMIM TFSI (see Table S1) and show that $T_{\text {start }}$ and $T_{\text {onset }}$ are much larger than $T_{0.01 / 10 \mathrm{~h}}$ or $T_{\mathrm{max}, 0.01 / \text { year }}$. Note that evaporation can occur and is usually not taken into account (except for $T_{\text {max }}, 0.01 /$ year in table S1), so that the loss of mass measured is a mixture of evaporation and degradation, leading to a possible overestimation of degradation (see ESI section S4.2. for more details). Therefore at our maximal temperature of analysis for the ferrofluids here in SANS $\left(200^{\circ} \mathrm{C}\right)$, EMIM TFSI can be considered as long-term stable, with no degradation and only evaporation. Concerning the other compounds of the
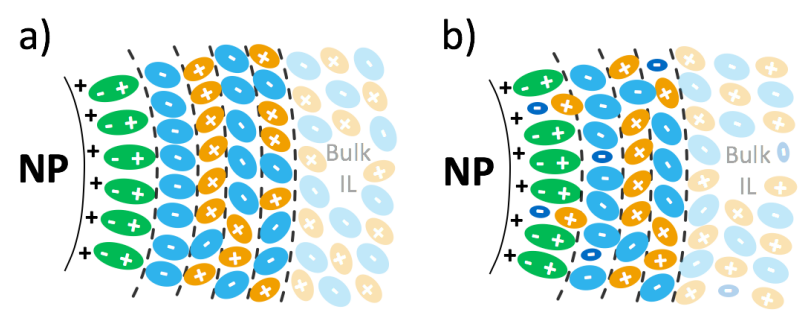

Figure 9: Schemes of possible organizations close to the NPs interface for the maximal surface charge density $\sigma \approx$ $30 \mu \mathrm{C} \mathrm{cm}^{-2}$ and the most stable systems in EMIM TFSI. (a) repulsive system, the third in the discussion, with $\mathrm{SBMIM}^{ \pm}$ zwitterions at the interface, $\left[\mathrm{SBMIM}^{ \pm}\right]=0.075 \mathrm{~mol} \mathrm{~L}^{-1}$. (b) attractive systems, the fourth in the discussion, with $\mathrm{SBMIM}^{ \pm}$ zwitterions and $\mathrm{TfO}^{-}$at the interface, $\left[\mathrm{SBMIM}^{ \pm}\right]=\left[\mathrm{TfO}^{-}\right]=$ $0.075 \mathrm{~mol} \mathrm{~L}^{-1}$.

final dispersions, less information is available and only on pure compounds when it exists. EMIM TfO has been studied, however not HSBMIM TFSI. HSBMIM was tested in literature with $\mathrm{HSO}_{4}^{-}$anions [51] and another sulfonate with a propyl group instead of a butyl, HSPMIM TfO, was also tested [52]. The average of their $T_{\text {onset }}$ values are in the same 
range as our results on HSBMIM TFSI.

In ionic liquids, the possible mechanisms of degradation have been explored. Chen et al. [58] analyzed the temperature stability by TGA-MS of EMIM TFSI and found in their experiments that above $350{ }^{\circ} \mathrm{C}$ first TFSI decomposes to more nucleophilic groups, such as $-\mathrm{F},-\mathrm{CF}_{3}$ and $-\mathrm{NH}_{2}$ that mainly attack the ethyl group of the cation EMIM by elimination and nucleophilic substitution mechanisms. The same is observed for BMIM TfO that also decomposes to methylimidazolium (MIM) and $\mathrm{HCF}_{3}$ [59]. Ethylimidazoles are the first species that are detected followed by methylimidazoles. $\mathrm{SO}_{2}$ is also detected for $\mathrm{TFSI}^{-}$and as well for $\mathrm{TfO}^{-}$ based ionic liquids. Nakurte et al [60] analyzed by electrospray ionization mass spectrometry (ESI-MS) the decomposition mechanisms of different zwitterions dissolved in water, one being close to the zwitterion $\mathrm{SBMIM}^{ \pm}$analyzed here but with a propyl instead of a butyl side chain. As observed in a lot of other studies for ionic liquids $[38,36,58]$ it is the longer side chain of the imidazolium ring that is cleaved in the highest proportion (here $60 \%$ in the mass spectrum) generating propanesulfonate and methylimidazolium. The second most probable mechanism is the elimination of sulfurous acid leaving methylpropyleneimidazolium (10\% in the mass spectrum).

From the literature, it appears that the thermal stability of ionic liquids is governed by nucleophilic anion attack of the cation. Thermal stability is therefore higher for lower nucleophilicity (i.e. higher Lewis basicity) [38]. As Lewis bases (for the anion) lower the degradation temperature, it is assumed that Lewis acids (for the cation) do as well. Hence, the (H)SBMIM could generate neutral molecules that evaporate.

From the measurements performed here on the components of the ferrofluids and on the ferrofluids, looking at $T_{\text {start }}$ or $T_{\text {onset }}$, the colloidal dispersions appear chemically slightly less stable than pure EMIM TFSI ( $T_{\text {start }}$ shifted down by $20-40^{\circ} \mathrm{C}$ ) which seems to originate from HSBMIM. However the chemical stability is fully preserved at $200{ }^{\circ} \mathrm{C}$ on the scale of hours as shown by the long isothermal TGA experiments on $15 \mathrm{~h}$ at $200^{\circ} \mathrm{C}$.

\subsubsection{High temperatures: microscopic analysis up to $200{ }^{\circ} \mathrm{C}$}

The microscopic analysis of these same dispersions by SANS, SAXS and DLS complements this TGA analysis with the nanostructure at high temperature. The in-situ measurements at high temperature indicate that the interparticle interactions do not significantly evolve while increasing $T$ up to $200{ }^{\circ} \mathrm{C}$. This is rather difficult to predict and even to interpret given the scarcity of studies at high temperatures. Indeed, the effect of temperature on colloidal stability can be examined from the point of view of interparticle forces [61]. In the systems studied here, particles are submitted to van der Waals and magnetic attractions. In order to prevent aggregation, some repulsion must counterbalance these forces. Among them, electrostatic interparticle interactions modeled with a Debye-Hückel expression is usually ruled out as to- tally screened because of the high concentration of ions [62]. Structural ionic interactions, stemming from the particular local organization of the IL solvent around the NPs in an ion layering close to the NPs' surface, correspond to a welldocumented phenomenon at room temperature that indeed prevents close approach of the particles. H-bonds can also occur [34], but the high $\mathrm{T}$ stability of the system also rules them out here. A steric contribution, here due to the $\mathrm{SBMIM}^{ \pm}$ layer may also occur. However, the relatively short range of the interaction balance (characteristic length $\simeq 1 \mathrm{~nm}$ ) observed by SANS and SAXS and its relative independence with temperature, is not compatible with the long-range repulsion, which has been frequently evidenced in ionic liquids and concentrated salt solutions by SFA force measurements $[29,30]$. This long-range force of purely electrostatic origin typically extends for EMIM TFSI between symmetric mica surfaces, on a characteristic spacial length $\kappa^{-1}$ of $6.6 \mathrm{~nm}$ at $22^{\circ} \mathrm{C}$ and decreases to $4.4 \mathrm{~nm}$ at $50^{\circ} \mathrm{C}$ [31], much larger than the value obtained here. The independence of the effective interparticle interaction on temperature obtained up to $200{ }^{\circ} \mathrm{C}$ here probably mainly result from the short range structuring forces of the ionic liquid. These forces are strongly dependent on the nature of the surface species and less dependent on T [31]. Moreover, a compensation between the variations of the different interactions can reduce this variation with temperature in the range $25-200{ }^{\circ} \mathrm{C} \mathrm{K}$.

\section{Conclusions and outlook}

The present study hypothesized that stable colloidal dispersions of nanoparticles (NPs) in ionic liquids (ILs) can be obtained by carefully adapting the NPs' interfacial properties with pure IL or adsorbed species and that they can be stable up to high temperatures, as high as $200{ }^{\circ} \mathrm{C}(473 \mathrm{~K})$. Although such systems at high temperature are envisaged for heat transfer fluids [13] or lubricants [33], the charge of the NPs is seldom considered and never varied. Moreover, the nanostructure of the dispersion at high temperature has only been considered recently by DLS in molten salts [35].

We show here how to change the dispersions state by playing on the NPs initial charge, which modulates the organization of the IL around the NPs in agreement with numerical simulations [16]. We also point at the role of the nature of the interfacial species and examine the role of the NPs volume fraction.

By associating transmission electron microscopy (TEM), dynamic light scattering (DLS), small angle scattering of Xrays (SAXS) or neutrons (SANS) for several compositions, we show that the pure IL alone does not provide colloidal stability to the dispersion. On the contrary, the zwitterion SBMIM $^{ \pm}$(a sulfonate imidazolium), which localizes at the NPs interface, can ensure stability at high NPs' charge density.

For the optimal amount of zwitterion at the maximal charge density of the NP, the colloidal stability is kept up to $200{ }^{\circ} \mathrm{C}(473 \mathrm{~K})$ for $\Phi_{\mathrm{NP}}$ from 1 to $12 \mathrm{vol} \%$, with a global interparticle interaction that stays rather constant with temper- 
ature. It is quantified by a positive second virial coefficient of the osmotic pressure $\mathrm{A}_{2} \simeq 8$ associated with a rather short repulsion length $\kappa^{-1} \simeq 1 \mathrm{~nm}$. Unlike what is proposed in [30], small angle scattering measurements are unable here to detect the long range repulsion observed by SFA force measurements between symmetric charged surfaces in most ILs. It means anyway that the induced interfacial organization of the ions of the ionic liquid is sufficient to counterbalance the attractive van der Waals and magnetic dipolar interparticle interactions and that any modification induced while heating is compensated so that the colloidal dispersion remains stable.

We also show how additional species, such as $\mathrm{TfO}^{-}$anions, can disturb the NPs-IL interface by localizing in this region and modify the NP-NP interaction, which becomes slightly attractive, with possible small aggregates. The obtained dispersions are nevertheless stable in the long run, over more than one year.

As the NPs are here magnetic, long-term stable ferrofluids are obtained stable over years at room temperature and at least on days at $200^{\circ} \mathrm{C}(473 \mathrm{~K})$, suited for the use in applications that require a broad range of temperatures. The method can be extended to other ionic liquids and our tests show that stable dispersions can be obtained even above room temperature. In the future, it would be interesting to apply the principles to disperse NPs based on various oxides or other materials in ionic liquids, chosen for their respective properties, in order to design task specific dispersions.

\section{Declaration of competing interest}

There are no conflicts of interest to declare.

\section{Authors contributions}

JR did most experiments and wrote the first draft in the frame of his $\mathrm{PhD}, \mathrm{ED}$ and VP supervised JR, added experiments and revised the text, JR,MS,TF,FC,ED,GM,RP,VP performed the scattering experiments. All the authors contributed to discussions and improvement of the text.

\section{Acknowledgements}

We thank Amandine Anfry for DLS measurements, Aude Michel for FAAS measurements, Arnaud Hélary for the design of the coupled DLS-SANS measurement setup at LLB (Laboratoire Léon Brillouin), and Sandra Casale for the TEM images taken at the IMPC (Institut des Matériaux de ParisCentre). We acknowledge the Laboratoire Léon Brillouin (CEA-Saclay, France) for neutron beamtime at the PAXY spetrometer. This work has been supported by the European Union Horizon 2020 research and innovation program under the grant number 731976 (MAGENTA), by the Brazilian agency CNPq and the bilateral program CAPES-COFECUB $\mathrm{Ph}$ 950/20 and by the laboratories own resources.

\section{Appendix A. Supplementary material}

Electronic Supplementary Information (ESI) to this article can be found online at link.

\section{References}

[1] T. Welton, Room-Temperature Ionic Liquids. Solvents for Synthesis and Catalysis, Chemical Reviews 99 (8) (1999) 2071-2084. doi:10. $1021 / \operatorname{cr} 980032 \mathrm{t}$

URL http://pubs.acs.org/doi/abs/10.1021/cr980032t

[2] L. Mestrom, J. J. M. Lenders, R. de Groot, T. Hooghoudt, N. A. J. M. Sommerdijk, M. V. Artigas, Stable ferrofluids of magnetite nanoparticles in hydrophobic ionic liquids, Nanotechnology 26 (28) (2015) 285602. doi : 10.1088/0957-4484/26/28/285602.

URL http://stacks.iop.org/0957-4484/26/i=28/a=285602?key= crossref. 39900d59c9edb1754ac24b6ebb3690ec

[3] D. R. MacFarlane, N. Tachikawa, M. Forsyth, J. M. Pringle, P. C. Howlett, G. D. Elliott, J. H. Davis, M. Watanabe, P. Simon, C. A. Angell, Energy applications of ionic liquids, Energy Environ. Sci. 7 (1) (2014) 232-250. doi:10.1039/C3EE42099J.

URL http://xlink.rsc.org/?DOI=C3EE42099J

[4] M. Armand, F. Endres, D. R. MacFarlane, H. Ohno, B. Scrosati, Ionic-liquid materials for the electrochemical challenges of the future, in: Materials For Sustainable Energy: A Collection of Peer-Reviewed Research and Review Articles from Nature Publishing Group, World Scientific, 2011, pp. 129-137.

[5] M. Bonetti, S. Nakamae, B. T. Huang, T. J. Salez, C. Wiertel-Gasquet, M. Roger, Thermoelectric energy recovery at ionic-liquid/electrode interface, The Journal of Chemical Physics 142 (24) (2015) 244708. arXiv: http://dx.doi.org/10.1063/1.4923199, doi:10.1063/1.4923199. URL http://dx.doi.org/10.1063/1.4923199

[6] E. Laux, S. Uhl, L. Jeandupeux, P. P. López, P. Sanglard, E. Vanoli, R. Marti, H. Keppner, Thermoelectric generators based on ionic liquids, Journal of Electronic Materials (2018) 1-5doi:10.1007/ s11664-018-6175-z.

URL https://doi.org/10.1007/s11664-018-6175-z

[7] M. Dupont, D. MacFarlane, J. Pringle, Thermo-electrochemical cells for waste heat harvesting - progress and perspectives, Chem. Commun. 53 (2017) 6288-6302.

[8] K. Paduszyński, U. Domańska, Viscosity of Ionic Liquids: An Extensive Database and a New Group Contribution Model Based on a FeedForward Artificial Neural Network, Journal of Chemical Information and Modeling 54 (5) (2014) 1311-1324. doi:10.1021/ci500206u.

URL http://pubs.acs.org/doi/10.1021/ci500206u

[9] Z. He, P. Alexandridis, Ionic liquid and nanoparticle hybrid systems: Emerging applications, Advances in Colloid and Interface Science 244 (2017) 54-70. doi :10.1016/j.cis.2016.08.004.

URL https://linkinghub.elsevier.com/retrieve/pii/ S0001868616302238

[10] T. J. Salez, B. T. Huang, M. Rietjens, M. Bonetti, C. Wiertel-Gasquet, M. Roger, C. L. Filomeno, E. Dubois, R. Perzynski, S. Nakamae, Can charged colloidal particles increase the thermoelectric energy conversion efficiency?, Physical Chemistry Chemical Physics 19 (14) (2017) 9409-9416. doi:10.1039/C7CP01023K.

URL http://xlink.rsc.org/?DOI=C7CP01023K

[11] P. Bose, S. Bhattacharya, Electrochemical cycling behavior of pyrrolidinium ionic liquid tethered $\mathrm{TiO} 2$ nanoparticle-hybrid electrolytes: Influence of grafting density, Journal of The Electrochemical Society 164 (12) (2017) H788-H797. doi : 10.1149/2.1331712jes.

URL https://doi.org/10.1149/2.1331712jes

[12] J. M. P. França, M. J. V. Lourenço, S. M. S. Murshed, A. A. H. Pádua, C. A. Nieto de Castro, Thermal Conductivity of Ionic Liquids and IoNanofluids and Their Feasibility as Heat Transfer Fluids, Industrial \& Engineering Chemistry Research 57 (18) (2018) 6516-6529. doi : 10.1021/acs. iecr. 7 b04770.

URL https://pubs.acs.org/doi/10.1021/acs. iecr. 7 b04770 
[13] A. A. Minea, S. M. Sohel Murshed, Ionic Liquids-Based Nanocolloids-A Review of Progress and Prospects in Convective Heat Transfer Applications, Nanomaterials 11 (4) (2021) 1039. doi:10.3390/ nano11041039.

URL https://www. mdpi . com/2079-4991/11/4/1039

[14] S. Bi, T. M. Koller, M. H. Rausch, P. Wasserscheid, A. P. Fröba, Dynamic Viscosity of Tetracyanoborate- and Tricyanomethanide-Based Ionic Liquids by Dynamic Light Scattering, Industrial \& Engineering Chemistry Research 54 (11) (2015) 3071-3081. doi : 10.1021/acs. iecr. 5 b00086.

URL https://pubs. acs.org/doi/10.1021/acs. iecr. 5b00086

[15] H. Zhang, K. Dasbiswas, N. B. Ludwig, G. Han, B. Lee, S. Vaikuntanathan, D. V. Talapin, Stable colloids in molten inorganic salts, Nature 542 (7641) (2017) 328-331. doi:10.1038/nature21041.

URL http://www. nature.com/articles/nature21041

[16] V. Kamysbayev, V. Srivastava, N. B. Ludwig, O. J. Borkiewicz, H. Zhang, J. Ilavsky, B. Lee, K. W. Chapman, S. Vaikuntanathan, D. V. Talapin, Nanocrystals in Molten Salts and Ionic Liquids: Experimental Observation of Ionic Correlations Extending beyond the Debye Length, ACS Nano 13 (5) (2019) 5760-5770. doi:10.1021/ acsnano. 9b01292.

URL http://pubs. acs.org/doi/10.1021/acsnano. 9b01292

[17] F. C. C. Oliveira, L. M. Rossi, R. F. Jardim, J. C. Rubim, Magnetic Fluids Based on $\gamma-\mathrm{Fe}_{2} \mathrm{O}_{3}$ and $\mathrm{CoFe}_{2} \mathrm{O}_{4}$ Nanoparticles Dispersed in Ionic Liquids, The Journal of Physical Chemistry C 113 (20) (2009) 8566-8572. doi: 10.1021/jp810501m.

URL http://pubs.acs.org/doi/abs/10.1021/jp810501m

[18] M. Mamusa, J. Siriex-Plénet, F. Cousin, E. Dubois, V. Peyre, Tuning the colloidal stability in ionic liquids by controlling the nanoparticles/liquid interface, Soft Matter 10 (8) (2014) 1097. doi:10.1039/ c3sm52733f.

URL http://xlink.rsc.org/?DOI=c3sm52733f

[19] M. Mamusa, J. Sirieix-Plénet, F. Cousin, R. Perzynski, E. Dubois, V. Peyre, Microstructure of colloidal dispersions in the ionic liquid ethylammonium nitrate: influence of the nature of the nanoparticles' counterion, Journal of Physics: Condensed Matter 26 (28) (2014) 284113. doi: $10.1088 / 0953-8984 / 26 / 28 / 284113$.

URL http://stacks.iop.org/0953-8984/26/i=28/a=284113?key= crossref. 4f747615a635a1f7f3b19376218d5f56

[20] J. C. Riedl, M. A. Akhavan Kazemi, F. Cousin, E. Dubois, S. Fantini, S. Loïs, R. Perzynski, V. Peyre, Colloidal dispersions of oxide nanoparticles in ionic liquids: elucidating the key parameters, Nanoscale Advances 2 (4) (2020) 1560-1572, publisher: Royal Society of Chemistry. doi:10.1039/C9NA00564A.

URL https://pubs.rsc.org/en/content/articlelanding/2020/na/ c9na00564a

[21] M. Mezger, H. Schroder, H. Reichert, S. Schramm, J. S. Okasinski, S. Schoder, V. Honkimaki, M. Deutsch, B. M. Ocko, J. Ralston, M. Rohwerder, M. Stratmann, H. Dosch, Molecular Layering of Fluorinated Ionic Liquids at a Charged Sapphire (0001) Surface, Science 322 (5900) (2008) 424-428. doi :10.1126/science. 1164502. URL http://www. sciencemag. org/cgi/doi/10.1126/science.1164502

[22] R. Hayes, N. Borisenko, M. K. Tam, P. C. Howlett, F. Endres, R. Atkin, Double layer structure of ionic liquids at the au(111) electrode interface: An atomic force microscopy investigation, J. Phys. Chem. C 115 (2011) 6855-6863.

[23] V. Ivaništšev, S. O'Connor, M. Fedorov, Poly(a)morphic portrait of the electrical double layer in ionic liquids, Electrochemistry Communications 48 (2014) 61-64. doi:10.1016/j. elecom. 2014.08.014. URL https://linkinghub.elsevier.com/retrieve/pii/ S1388248114002690

[24] C. Guibert, V. Dupuis, J. Fresnais, V. Peyre, Controlling nanoparticles dispersion in ionic liquids by tuning the $\mathrm{pH}$, Journal of Colloid and Interface Science 454 (2015) 105-111. doi : 10.1016/j. jcis. 2015.04.059.

URL https://linkinghub.elsevier.com/retrieve/pii/ S0021979715004361

[25] K. Bhattacharya, M. Sarkar, T. J. Salez, S. Nakamae, G. Demouchy,
F. Cousin, E. Dubois, L. Michot, R. Perzynski, V. Peyre, Structural, Thermodiffusive and Thermoelectric Properties of Maghemite Nanoparticles Dispersed in Ethylammonium Nitrate, ChemEngineering 4 (1) (2020) 5, number: 1 Publisher: Multidisciplinary Digital Publishing Institute. doi : 10.3390/chemengineering 4010005.

URL https: //www. mdpi . com/2305-7084/4/1/5

[26] J. Nordström, L. Aguilera, A. Matic, Effect of Lithium Salt on the Stability of Dispersions of Fumed Silica in the Ionic Liquid BMImBF ${ }_{4}$, Langmuir 28 (9) (2012) 4080-4085. doi : 10.1021/1a204555g. URL http://pubs.acs.org/doi/10.1021/la204555g

[27] A. Elbourne, S. McDonald, K. Voïchovsky, F. Endres, G. G. Warr, R. Atkin, Nanostructure of the Ionic Liquid-Graphite Stern Layer, ACS Nano 9 (7) (2015) 7608-7620. doi:10.1021/acsnano. 5b02921. URL http://pubs.acs.org/doi/10.1021/acsnano. 5b02921

[28] R. Hayes, N. Borisenko, B. Corr, G. B. Webber, F. Endres, R. Atkin, Effect of dissolved $\mathrm{LiCl}$ on the ionic liquid-Au(111) electrical double layer structure, Chemical Communications 48 (82) (2012) 10246. doi : 10.1039/c2cc35737b.

URL http://xlink. rsc. org/?DOI=c2cc35737b

[29] J. Zeman, S. Kondrat, C. Holm, Bulk ionic screening lengths from extremely large-scale molecular dynamics simulations, Chem. Commun. 56 (2020) 15635-15638. doi :10.1039/D0cc05023G. URL http://dx. doi .org/10.1039/D0cC05023G

[30] M. A. Gebbie, A. M. Smith, H. A. Dobbs, A. A. Lee, G. G. Warr, X. Banquy, M. Valtiner, M. W. Rutland, J. N. Israelachvili, S. Perkin, R. Atkin, Long range electrostatic forces in ionic liquids, Chemical Communications 53 (7) (2017) 1214-1224. doi : 10.1039/c6cc08820A. URL http: //xlink.rsc.org/?DOI=C6CC08820A

[31] M. A. Gebbie, H. A. Dobbs, M. Valtiner, J. N. Israelachvili, Longrange electrostatic screening in ionic liquids, Proc Natl Acad Sci USA 112 (24) (2015) 7432-7437. doi : 10.1073/pnas. 1508366112.

URL http://www. pnas.org/lookup/doi/10.1073/pnas. 1508366112

[32] N. Hjalmarsson, R. Atkin, M. W. Rutland, Switchable long-range double layer force observed in a protic ionic liquid, Chemical Communications 53 (3) (2017) 647-650, number: 3. doi:10.1039/C6cC07396D. URL http: //xlink.rsc.org/?DOI=C6cc07396D

[33] X. Shi, W. Huang, X. Wang, Ionic liquids-based magnetic nanofluids as lubricants, Lubrication Science 30 (2) (2018) 73-82. doi : 10.1002/ 1s. 1405.

URL http://doi.wiley.com/10.1002/1s. 1405

[34] J. Gao, P. M. Mwasame, N. J. Wagner, Thermal rheology and microstructure of shear thickening suspensions of silica nanoparticles dispersed in the ionic liquid $\left[\mathrm{C}_{4} \mathrm{mim}\right]\left[\mathrm{BF}_{4}\right]$, Journal of Rheology 61 (3) (2017) 525-535. doi: 10.1122/1.4979685.

URL http://sor. scitation.org/doi/10.1122/1.4979685

[35] N. Navarrete, A. Gimeno-Furió, J. Forner-Escrig, J. E. Juliá, R. Mondragón, Colloidal stability of molten salt -based nanofluids: Dynamic Light Scattering tests at high temperature conditions, Powder Technology 352 (2019) 1-10. doi : 10. 1016/j. powtec. 2019.04.045. URL S0032591019302931

[36] Y. Cao, T. Mu, Comprehensive Investigation on the Thermal Stability of 66 Ionic Liquids by Thermogravimetric Analysis, Ind. Eng. Chem. Res. 53 (20) (2014) 8651-8664. doi:10.1021/ie5009597.

URL https://pubs. acs.org/doi/10.1021/ie5009597

[37] S. Werner, M. Haumann, P. Wasserscheid, Ionic Liquids in Chemical Engineering, in: Prausnitz, JM and Doherty, MF and Segalman, RA (Ed.), Annual Review of Chemical and Biomolecular Engineering, Vol 1, Vol. 1 of Annual Review of Chemical and Biomolecular Engineering, Annual Reviews, 2010, pp. 203-230. doi :10.1146/ annurev-chembioeng-073009-100915.

[38] C. Maton, N. D. Vos, C. V. Stevens, Ionic liquid thermal stabilities: decomposition mechanisms and analysis tools, Chemical Society Reviews 42 (13) (2013) 5963-5977. doi : 10.1039/C3cs60071H.

URL https://pubs.rsc.org/en/content/articlelanding/2013/cs/ c3cs60071h

[39] R. Massart, Preparation of aqueous magnetic liquids in alkaline and acidic media, IEEE transactions on magnetics 17 (2) (1981) 1247- 
1248.

[40] J.-P. Jolivet, E. Tronc, Interfacial electron transfer in colloidal spinel iron oxide. Conversion of $\mathrm{Fe}_{3} \mathrm{O}_{4}-\gamma-\mathrm{Fe}_{2} \mathrm{O}_{3}$ in aqueous medium, Journal of Colloid and Interface Science 125 (2) (1988) 688-701. doi : 10.1016/0021-9797(88)90036-7.

URL http://linkinghub.elsevier.com/retrieve/pii/ 0021979788900367

[41] I. T. Lucas, S. Durand-Vidal, E. Dubois, J. Chevalet, P. Turq, Surface Charge Density of Maghemite Nanoparticles: Role of Electrostatics in the Proton Exchange, J. Phys. Chem. C 111 (50) (2007) 1856818576. doi: $10.1021 / \mathrm{jp} 0743119$.

URL https://pubs.acs.org/doi/10.1021/jp0743119

[42] M. Mamusa, J. Sirieix-Plénet, R. Perzynski, F. Cousin, E. Dubois, V. Peyre, Concentrated assemblies of magnetic nanoparticles in ionic liquids, Faraday Discussions 181 (2015) 193-209. doi:10.1039/ C5FD00019J.

URL http://xlink.rsc.org/?D0I=C5FD00019J

[43] N. F. Carnahan, K. E. Starling, Thermodynamic Properties of a RigidSphere Fluid, The Journal of Chemical Physics 53 (2) (1970) 600603. doi:10.1063/1.1674033.

URL http://aip.scitation.org/doi/10.1063/1.1674033

[44] J. A. Barker, D. Henderson, Perturbation Theory and Equation of State for Fluids. II. A Successful Theory of Liquids, The Journal of Chemical Physics 47 (11) (1967) 4714-4721. doi : 10.1063/1.1701689. URL http://aip.scitation.org/doi/10.1063/1.1701689

[45] M. Sarkar, J. C. Riedl, G. Demouchy, F. Gélébart, G. Mériguet, V. Peyre, E. Dubois, R. Perzynski, Inversion of thermodiffusive properties of ionic colloidal dispersions in water-DMSO mixtures probed by forced Rayleigh scattering, Eur. Phys. J. E 42 (6) (2019) 72. doi : 10.1140/epje/i2019-11835-6. URL https://doi .org/10.1140/epje/i2019-11835-6

[46] M. Kouyaté, C. L. Filomeno, G. Demouchy, G. Mériguet, S. Nakamae, V. Peyre, M. Roger, A. Cēbers, J. Depeyrot, E. Dubois, R. Perzynski, Thermodiffusion of citrate-coated $\gamma$ - $\mathrm{Fe}{ }_{2} o_{3}$ nanoparticles in aqueous dispersions with tuned counter-ions - anisotropy of the Soret coefficient under a magnetic field, Physical Chemistry Chemical Physics 21 (2019) 1895-1903. doi:10.1039/C8CP06858E.

[47] E. Wandersman, A. Cēbers, E. Dubois, G. Mériguet, A. Robert, R. Perzynski, The cage elasticity and under-field structure of concentrated magnetic colloids probed by small angle X-ray scattering, Soft Matter 9 (48) (2013) 11480. doi:10.1039/c3sm51961a. URL http: //xlink.rsc.org/?DOI=c3sm51961a

[48] C. L. Filomeno, M. Kouyaté, V. Peyre, G. Demouchy, A. F. C. Campos, R. Perzynski, F. A. Tourinho, E. Dubois, Tuning the Solid/Liquid Interface in Ionic Colloidal Dispersions: Influence on Their Structure and Thermodiffusive Properties, The Journal of Physical Chemistry C 121 (10) (2017) 5539-5550. doi : 10.1021/acs. jpcc. 6b10280. URL http://pubs.acs.org/doi/10.1021/acs. jpcc. 6b10280

[49] C. Lopes Filomeno, M. Kouyaté, F. Cousin, G. Demouchy, E. Dubois, L. Michot, G. Mériguet, R. Perzynski, V. Peyre, J. Sirieix-Plénet, F. Tourinho, Ionic magnetic fluids in polar solvents with tuned counter-ions, Journal of Magnetism and Magnetic Materials 431 (2017) 2-7. doi:10.1016/j.jmmm.2016.07.050.

URL https://linkinghub.elsevier.com/retrieve/pii/ S0304885316315633

[50] R. Cabreira Gomes, A. Ferreira da Silva, M. Kouyaté, G. Demouchy, G. Mériguet, R. Aquino, E. Dubois, S. Nakamae, M. Roger, J. Depeyrot, R. Perzynski, Thermodiffusion of repulsive charged nanoparticles - the interplay between single-particle and thermoelectric contributions, Phys. Chem. Chem. Phys. 20 (24) (2018) 16402-16413. doi : $10.1039 / \mathrm{C} 8 \mathrm{CP} 02558 \mathrm{D}$.

URL http://xlink.rsc. org/?DOI=C8CP02558D

[51] J. Gui, H. Ban, X. Cong, X. Zhang, Z. Hu, Z. Sun, Selective alkylation of phenol with tert-butyl alcohol catalyzed by Brönsted acidic imidazolium salts, Journal of Molecular Catalysis A: Chemical 225 (1) (2005) 27-31. doi : 10.1016/j.molcata. 2004.08.026. URL https://linkinghub.elsevier.com/retrieve/pii/ S1381116904006077
[52] A. S. Amarasekara, O. S. Owereh, Thermal properties of sulfonic acid group functionalized Brönsted acidic ionic liquids, J Therm Anal Calorim 103 (3) (2011) 1027-1030. doi:10.1007/s10973-010-1101-5. URL http://link. springer. com/10.1007/s10973-010-1101-5

[53] F. Heym, B. J. M. Etzold, C. Kern, A. Jess, Analysis of evaporation and thermal decomposition of ionic liquids by thermogravimetrical analysis at ambient pressure and high vacuum, Green Chem. 13 (6) (2011) 1453. doi:10.1039/c0gc00876a.

URL http://xlink.rsc. org/?DOI=c0gc00876a

[54] V. Ivanistsev, M. V. Fedorov, Interfaces between Charged Surfaces and Ionic Liquids: Insights from Molecular Simulations, Interface magazine 23 (1) (2014) 65-69. doi : 10.1149/2.F08141if.

URL https://iopscience. iop.org/article/10.1149/2.F08141 if

[55] S. A. Kislenko, Y. O. Moroz, K. Karu, V. B. Ivaništšev, M. V. Fedorov, Calculating the Maximum Density of the Surface Packing of Ions in Ionic Liquids, Russian Journal of Physical Chemistry A 92 (5) (2018) 999-1005. doi: 10.1134/S0036024418050187.

URL ht tp: //link. springer. com/10.1134/S0036024418050187

[56] X. Lu, S. Deng, B. Wang, J. Huang, Y. Wang, G. Yu, Adsorption behavior and mechanism of perfluorooctane sulfonate on nanosized inorganic oxides, Journal of Colloid and Interface Science 474 (2016) 199-205. doi: 10.1016/j. jcis. 2016.04.032.

URL https://linkinghub.elsevier.com/retrieve/pii/ S0021979716302521

[57] A. Seeberger, A.-K. Andresen, A. Jess, Prediction of long-term stability of ionic liquids at elevated temperatures by means of nonisothermal thermogravimetrical analysis, Phys. Chem. Chem. Phys. 11 (41) (2009) 9375. doi: 10.1039/b909624h. URL http://xlink.rsc.org/?DOI=b909624h

[58] Y. Chen, Y. Cao, Y. Shi, Z. Xue, T. Mu, Quantitative Research on the Vaporization and Decomposition of [EMIM] $\left[\mathrm{Tf}_{2} \mathrm{~N}\right.$ ] by Thermogravimetric Analysis-Mass Spectrometry, Ind. Eng. Chem. Res. 51 (21) (2012) 7418-7427. doi : 10.1021/ie300247v. URL https://pubs. acs.org/doi/10.1021/ie300247v

[59] H. Ohtani, S. Ishimura, M. Kumai, Thermal Decomposition Behaviors of Imidazolium-type Ionic Liquids Studied by PyrolysisGas Chromatography, Anal. Sci. 24 (10) (2008) 1335-1340. doi:10.2116/analsci.24.1335.

URL http://joi.jlc.jst.go.jp/JST. JSTAGE/analsci/24.1335? from= CrossRef

[60] I. Nakurte, P. Mekss, K. Klavins, A. Zicmanis, G. Vavilina, S. Dubrovina, Collision-Induced Dissociation of Imidazolium-Based Zwitterionic Liquids, Eur J Mass Spectrom (Chichester) 15 (4) (2009) 471-478. doi:10.1255/ejms. 997.

URL http://journals. sagepub. com/doi/10.1255/ejms. 997

[61] Z. He, P. Alexandridis, Nanoparticles in ionic liquids: interactions and organization, Physical Chemistry Chemical Physics 17 (28) (2015) 18238-18261. doi:10.1039/C5CP01620G. URL http://xlink.rsc.org/?DOI=C5CP01620G

[62] R. Kjellander, Nonlocal electrostatics in ionic liquids: The key to an understanding of the screening decay length and screened interactions, The Journal of Chemical Physics 145 (12) (2016) 124503. arXiv: https://doi .org/10.1063/1.4962756, doi:10.1063/1.4962756. URL https://doi .org/10.1063/1.4962756 


\title{
Design of concentrated colloidal dispersions of iron oxide nanoparticles in ionic liquids: structure and thermal stability from 25 to $200^{\circ} \mathrm{C}$
}

\author{
J. C. RiedI ${ }^{1}$, M. Sarkar ${ }^{1}$, T. Fiuza ${ }^{1,2}$, F. Cousin ${ }^{3}$, J. Depeyrot ${ }^{2}$, E. Dubois ${ }^{1,}$, , G. Mériguet $^{1}$, R. \\ Perzynski ${ }^{1}$, and V. Peyre ${ }^{1, *}$
}

${ }^{1}$ Sorbonne Université, Laboratoire PHENIX, 4 place Jussieu, case 51, 75005, Paris, France

${ }^{2}$ Inst. de Fisica, Complex Fluid Group, Universidade de Brasília, Brasília, Brazil

${ }^{3}$ Laboratoire Léon Brillouin, UMR CNRS 12, CE Saclay, Gif sur Yvette, France

*emmanuelle.dubois@sorbonne-universite.fr, veronique.peyre@sorbonne-universite.fr

\section{SUPPLEMENTARY INFORMATION}

\section{S1 Materials}

The following materials were used without further purification: Sodium hydroxide $(\mathrm{NaOH}$ pellets, $98 \%$, Acros Organics); hydrochloric acid ( $\mathrm{HCl}, 37 \%$ water solution, AnalaR Normapur); iron(II) chloride $\left(\mathrm{FeCl}_{2} * 4 \mathrm{H}_{2} \mathrm{O}\right.$, AnalaR Normapur, VWR); iron(III) chloride $\left(\mathrm{FeCl}_{3} * 6 \mathrm{H}_{2} \mathrm{O}\right.$, Prolabo); iron(III) nitrate $\left(\mathrm{Fe}\left(\mathrm{NO}_{3}\right)_{3} * 9 \mathrm{H}_{2} \mathrm{O}\right.$, technical, VWR); triflic acid (HTfO, $49.2 \mathrm{wt} \%$ in water, purity $99 \%$, SOLVIONIC); N,N-Bis(trifluoromethanesulfonyl)imide acid (HTFSI, purity $95 \%$, Fluorochem); 1-(4-Sulfobutyl)-3-methylimidazolium bistriflimide (HSBMIM TFSI, purity 98 \%, SOLVIONIC); 1-(4-Sulfobutyl)-3methylimidazolium triflate (HSBMIM TfO, purity $98 \%$, SOLVIONIC); 1-(4-Sulfobutyl)-3-methylimidazolium (SBMIM ${ }^{ \pm}$, purity $98 \%$, SOLVIONIC).

\section{S2 Techniques}

\section{S2.1 Dynamic Light Scattering (DLS)}

Light scattering measurements were performed using different Vasco DLS Particle Analyzers from Cordouan Technologies. These devices have been designed for dark and absorbing media. All use a fixed angle in backscattering and the laser power can be tuned.

For the Vasco, the laser of the device is operating at a wavelength $\lambda=656 \mathrm{~nm}$ and the detection is at $135^{\circ}$ (i.e. $\mathrm{Q}=2.35^{*} 10^{-3}$ $\AA^{-1}$ in water). The sample is a thin liquid film of thickness around $200 \mu \mathrm{m}$ enclosed in an optical cell. These conditions prevent both the effects of light absorption by the colloidal suspension and multiple scattering even in strongly absorbing media ${ }^{1}$. The detection is homodyne. Field autocorrelation curves with a precise baseline at long times were obtained by optimizing parameters such as the incident laser power, the sampling time and the number of channels. The measured intensity correlation function $\mathrm{G}(\mathrm{t})$ was transformed into $\mathrm{G}_{1}(\mathrm{t})$ using the expression:

$$
G_{1}(t)=[G(t)]^{1 / 2}-\text { offset }
$$

The normalized intensity auto correlation functions $\mathrm{G}_{1}(\mathrm{t})$ were analysed with a stretched exponential function, $\mathrm{e}^{-(\mathrm{t} / \tau)^{\beta}}$ with a distribution of relaxation times described by a decay time $\tau$ and a stretching exponent $\beta$. The nanoparticle translation time $\tau$ is probed. It corresponds to the translational diffusion coefficient $\mathrm{D}_{t}=\left(<\tau>\mathrm{Q}^{2}\right)^{-1}$, which, in non-interacting conditions, is related to the hydrodynamic diameter $d_{H}$ using Stokes-Einstein's equation:

$$
D_{\mathrm{t}}=\frac{k_{\mathrm{B}} T}{3 \pi \eta d_{\mathrm{H}}}
$$

where $\mathrm{k}_{\mathrm{B}}$ is the Boltzmann constant, $\mathrm{T}$ the absolute temperature, $\eta$ the solvent shear-viscosity $\left(0.89^{*} 10^{-3} \mathrm{~Pa}\right.$ s for water and $34 * 10^{-3} \mathrm{~Pa}$ s for EMIM TFSI ${ }^{2}$ ) at $\mathrm{T}=25^{\circ} \mathrm{C}$ at which all experiments were performed. 
For the VascoFlex and VascoKin devices, the laser of the device is operating at a wavelength $\lambda=638 \mathrm{~nm}$ and the detection is at $170^{\circ}$ (i.e. $\mathrm{Q}=2.61 * 10^{-3} \AA^{-1}$ in water, $\mathrm{Q}=2.8^{*} 10^{-3} \AA^{-1}$ in EMIM TFSI). The data are analyzed in the same way as described above for the Vasco. VascoFlex and VascoKin have been used for the coupled SANS/DLS experiments, with flat quartz cells (see Figure S.3.a). For all other DLS experiments, either Vasco or VascoKin were used, the latter with other types of flat cells or glass tubes.

For all the measurements, the data have been fitted down to $\mathrm{G}_{1}=0.2$ and the stretching exponent $\beta$ is close to 1 . An example is shown in Figure S1. It has been checked that several consecutive experiments are superimposed. Moreover, the power of the laser is always chosen to be as small as possible and several powers have been tested with the VascoKin. It is always lower than $1.5 \mathrm{~mW}$ and down to $0.3 \mathrm{~mW}$ and the measurements for different powers were superimposed. Note that the particles strongly absorb in the green or more energetic wavelengths. The red is therefore the most favorable wavelength. Another element comes from Forced Rayleigh Scattering (FRS) experiments: the absorption of the sample is used to heat, however red wavelength are unable to heat it and a red laser (around $3 \mathrm{~mW}$ on the sample) is used to probe the grating of temperature induced by a high power lamp $(\simeq 400 \mathrm{~W})$ at more energetic wavelengths. Such experiments on the same samples as in the present study are published in reference ${ }^{3}$.

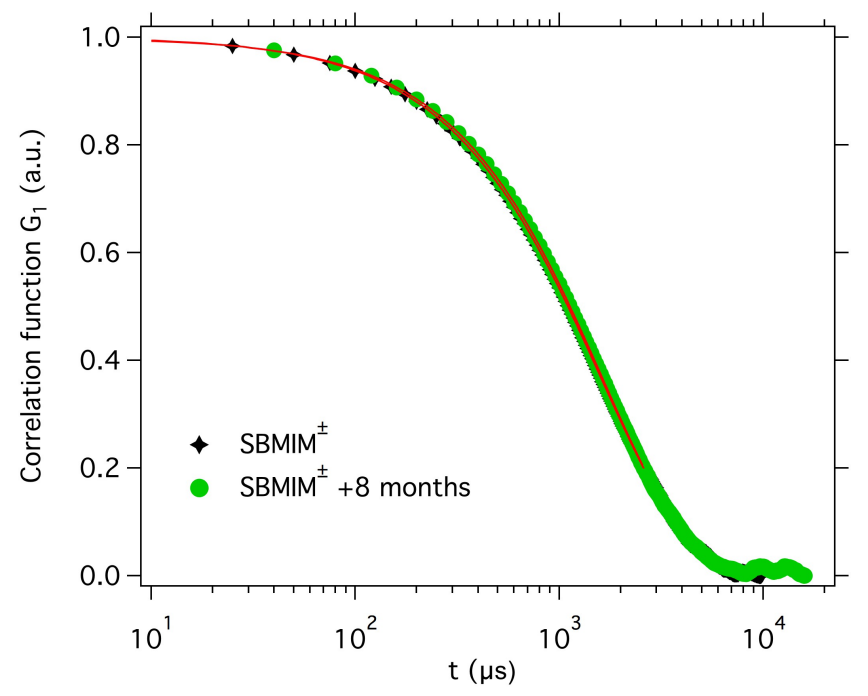

Figure S1. Example of DLS measurements in EMIM TFSI for NPs at $\Phi_{\mathrm{NP}}=1$ vol\% with $\left[\mathrm{SBMIM}^{ \pm}\right]=0.075 \mathrm{~mol} \mathrm{~L}^{-1}$. Same sample measured 8 months later.

\section{S2.2 Small Angle X-ray and neutron Scattering (SAXS and SANS)}

SAXS experiments were carried out with a laboratory XEUSS $2.0(\mathrm{~W}) \mathrm{SAXS}$. The beam energy was fixed at $8 \mathrm{keV}$ and the wavelength at $\lambda=1.54 \AA$. The sample to detector distance was $2.48 \mathrm{~m}$ to yield an accessible $Q$-range of $0.0045 \AA^{-1}-0.2 \AA^{-1}$. The experiments were performed with a collimated beam size of $0.5 \times 0.5 \mathrm{~mm}^{2}$, which provides an $\mathrm{x}$-ray flux of $\simeq 7.10^{6}$ photons.seconds ${ }^{-1}$. The integrated incident beam energy flux was $8.10^{3} \times 1 \cdot 6 \cdot 10^{-19} \times 7.10^{6}=9 \cdot 10^{-9} \mathrm{~J} \mathrm{~s}^{-1}$. The samples absorb $\mathrm{X}$-rays due to the ionic liquid EMIM TFSI and due to the iron atoms. Therefore thin capillaries were needed and the best compromise between absorption and scattered signal was obtained with $0.1 \mathrm{~mm}$ thick borosilicate capillaries from Vitrocom ${ }^{\circledR}$.

However, the wall thickness of $0.07 \mathrm{~mm}$ has an error of $\pm 20 \%$ and the interior thickness error is $\pm 10 \%$. As a consequence, absolute intensity could hardly be determined and the high $Q$ region $\left(>0.1 \AA^{-1}\right)$ was rather noisy. Therefore, the nanoparticle volume fraction together with the SANS measurements were used to adjust the SAXS curves to absolute intensities. The details on SANS measurements are given in section S.4.1. This comparison SANS/SAXS is also important to check that the absorption of X-Rays does not perturbate the system. This can also be confirmed from the estimation of the photon flux. The measured beam absorption was in a range $55 \%$ to $90 \%$, depending on the sample, as obtained from transmissions. Then, the energy transferred was between $4.9510^{-9}$ Joules s$^{-1}$ and $8.110^{-9}$ Joules s$^{-1}$ in an irradiated volume of $0.5 \times 0.5 \times 0.1=0.025 \mathrm{~mm}^{3}$ (which is equivalent to an irradiating rate ranging between $0.19 \mathrm{~Gy} \mathrm{~s}^{-1}$ and $0.29 \mathrm{~Gy} \mathrm{~s}^{-1}$ ), which is negligible to provide any heating of the samples. 


\section{S2.3 Flame Atomic Absorption Spectroscopy (FAAS)}

The maghemite-based ferrofluids were dissolved in a concentrated hydrochloric acid solution and their total iron concentration were determined by flame atomic absorption measurements (FAAS) with an Analyst 100 spectrometer from PerkinElmer. The volume fractions $\phi$ were determined from the total iron concentration in the sample. Taking the molar weight $\left(159.7 \mathrm{~g} \mathrm{~mol}^{-1}\right)$ and density $\left(4.87 \mathrm{~g} \mathrm{~cm}^{-3}\right)$ of maghemite, ${ }^{4}$ the volume fraction of NPs can be calculated as: $\phi(\mathrm{vol} \%)=[\mathrm{Fe}]\left(\mathrm{mol} \mathrm{L}^{-1}\right)^{* 1.577}$.

\section{S3 Additional results on colloidal stability at room temperature - $1 \mathrm{vol} \%$ of NPs}

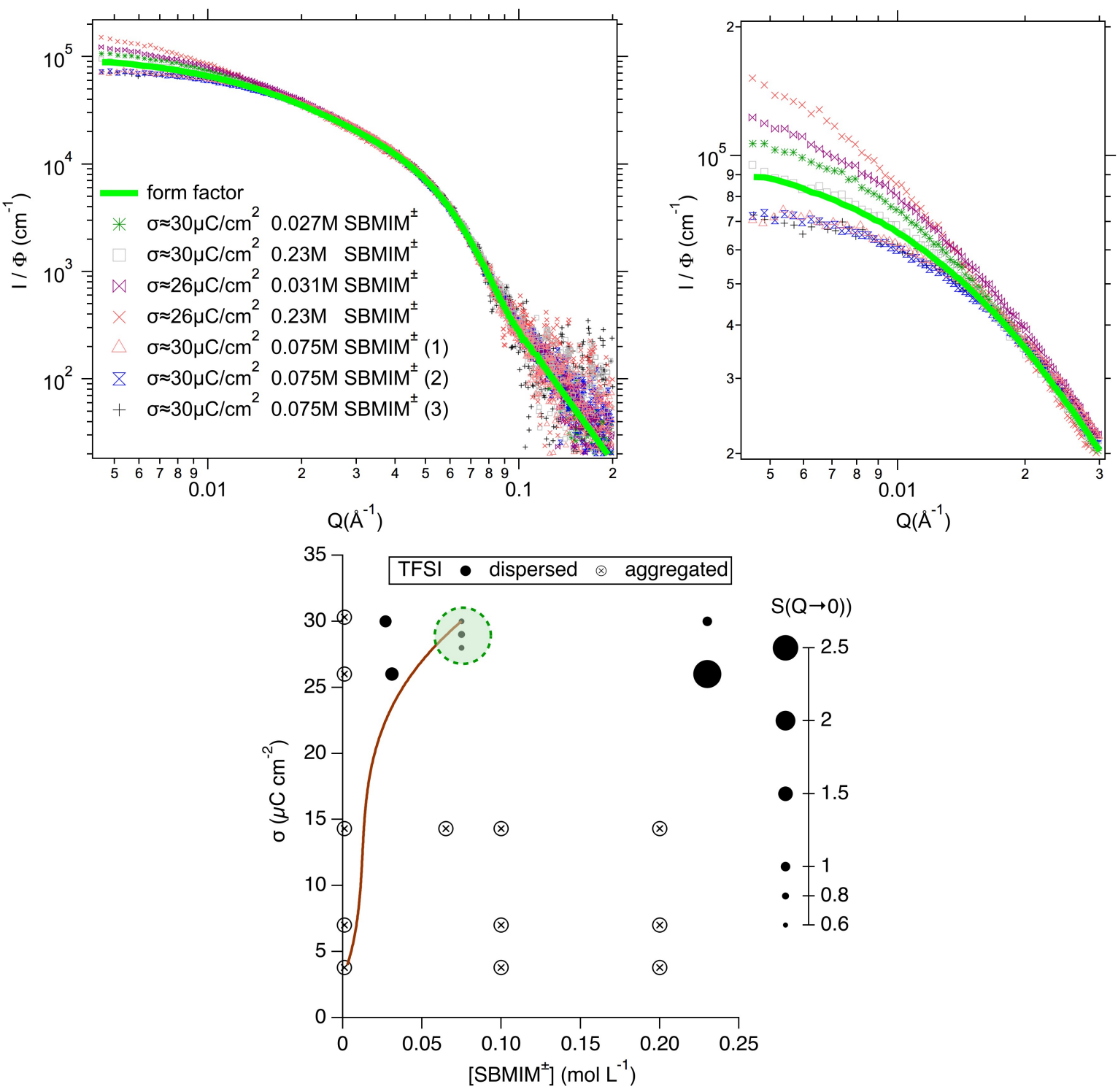

Figure S2. Top left) Absolute scattered intensities (normalized by the nanoparticle volume fraction $\Phi_{\mathrm{NP}} \approx 0.8-1$ vol\%) as a function of Q obtained by SAXS for nanoparticle dispersions in EMIM TFSI at various [SBMIM ${ }^{ \pm}$] and initial charge density $\sigma$ of the NPs in water. The samples are prepared with the two step process (acid first, then $\mathrm{SBMIM}^{ \pm}$zwitterion) except the last three, marked (1), (2), and (3). They are prepared with the one step process in the same way to test the reproducibility (see text for details). Top right) Zoom of the small Q region that clearly shows the difference between the samples as well as the good reproducibility for several independent preparations; Bottom) The corresponding $S(Q \rightarrow 0)$ values for the samples which are not aggregated are mapped as disks of variable diameter in the plane $\sigma$ versus $\left[\mathrm{SBMIM}^{ \pm}\right.$]. The (calculated) brown line corresponds to a ratio 1 between $\mathrm{SBMIM}^{ \pm}$and $\mathrm{TFSI}^{-}$. The green area points towards the best parameters $\sigma$ and $\left[\mathrm{SBMIM}^{ \pm}\right.$] to obtain the most repulsive samples with well dispersed NPs. 
Figure S2 presents SAXS results for some of the samples presented in Figure $2 \mathrm{a}$ of the main text. The values $\mathrm{S}(\mathrm{Q} \rightarrow 0)$ are presented as disks of variable diameter in the diagram of the bottom of Figure S2 (plane of the charge density $\sigma$ versus $\left.\left[\mathrm{SBMIM}^{ \pm}\right]\right)$as in Figure $2 \mathrm{a}$ of the main text. It shows that the lowest $\mathrm{S}(\mathrm{Q} \rightarrow 0)$ values are obtained in the green area. This result is in agreement with the conclusions deduced from DLS in Figure 2a of the main text. However, SAXS enables to separate the existence of aggregates from hidden viscosity effects.

Indeed, the doubt in DLS comes from the uncertainty on the viscosity of the medium in the present case. The apparent hydrodynamic diameter $d_{H}$ is extracted from the Stokes-Einstein relation (Equation S2) forgetting the interparticle interaction and using only the viscosity of EMIM TFSI.

However in the studied dispersions, HTFSI is introduced first to tune the NPs' charge, then $\mathrm{SBMIM}^{ \pm}$is added to vary the ratio between $\mathrm{TFSI}^{-}$and $\mathrm{SBMIM}^{ \pm}$(two step process). Part of the $\mathrm{SBMIM}^{ \pm}$moves to the NPs interface, and the other part can either stay in the IL or can catch an $\mathrm{H}^{+}$to form HSBMIM. In this latter case, the dispersing medium becomes a mixture of EMIM TFSI and HSBMIM TFSI (this latter being considered as an additive given the low amount introduced). HSBMIM TFSI is an ionic liquid of very high viscosity $\left(\approx 1700 \mathrm{cP}\right.$ at $\left.25^{\circ} \mathrm{C}\right)$, which could thus change the viscosity of the dispersing medium. A factor up to 2 can be estimated for the maximal amount of HSBMIM TFSI in the solvent if we assume a linear influence of its weight fraction on the viscosity for these low concentrations. Hence, the apparent hydrodynamic diameter plotted could be overestimated by a factor of up to 2 .

Figure $\mathrm{S} 2$ shows that the $\mathrm{S}(\mathrm{Q} \rightarrow 0)$ values reproduce the same trend as $\mathrm{d}_{H}$ however less pronounced. This confirms that it is mainly the nanostructure that changes, even if an additional influence of the viscosity with increasing $\mathrm{SBMIM}^{ \pm}$concentration is observed in Figure 2 of the main text.

SAXS also clearly shows that several sample preparations with the same composition are perfectly reproducible, the SAXS curves being superimposed (Figure S2). This was done on samples at the maximal charge in water with the "one step process" adding the HSBMIM TFSI ionic liquid directly, which also improves reproducibility.

\section{S4 Thermal Stabilities}

\section{S4.1 Coupled SANS and DLS measurements}

DLS and SANS measurements were coupled at temperatures up to $200{ }^{\circ} \mathrm{C}(473 \mathrm{~K})$.
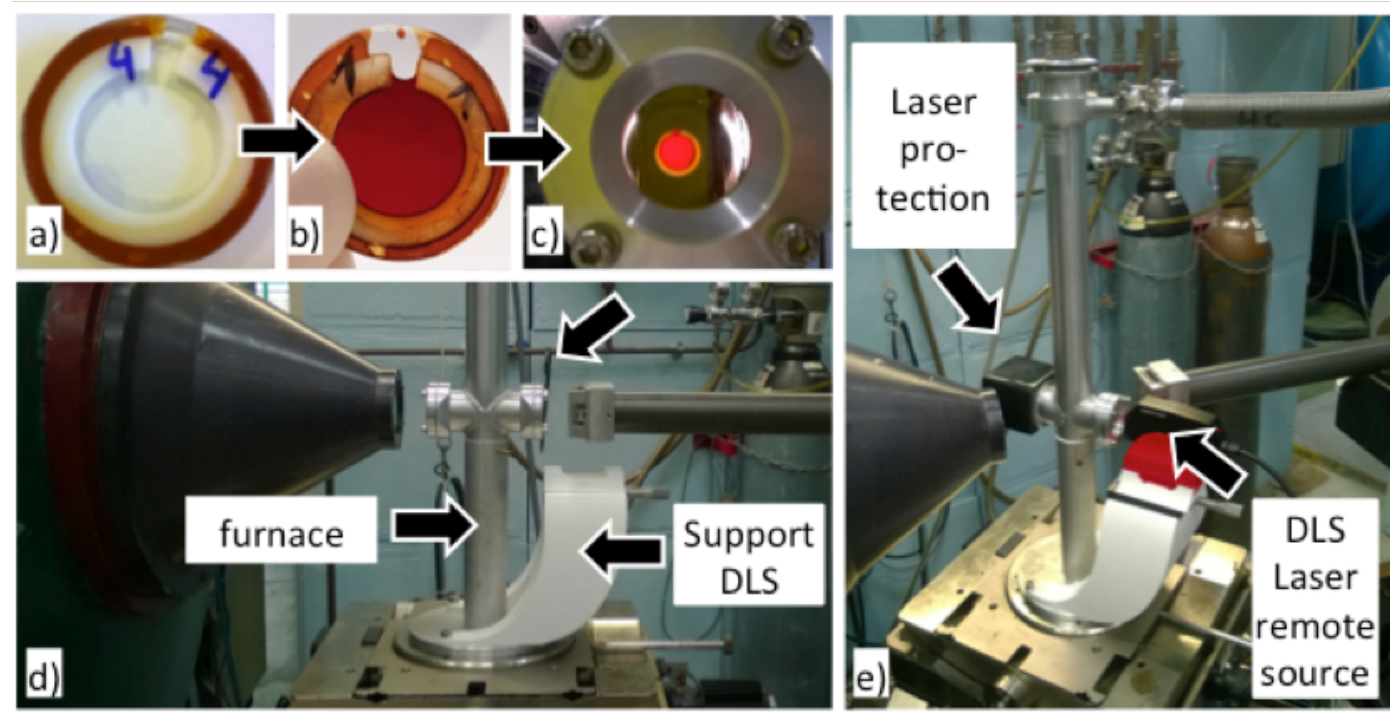

Figure S3. Scheme of the coupled SANS and DLS measurement setup at the PAXY spectrometer. a) Circular quartz/spacer/quartz sandwich with a hole on the top to evacuate gases that may form during the heating process at elevated temperatures. In b) this cell is filled with a sample and in c) it is in the furnace. d) Shows the configuration for SANS measurements and e) for DLS measurements.

Figure S3 shows the setup of the experiments performed at PAXY, LLB. A furnace was fixed on a controlled rotating table to ensure a reproducible position for all samples. The oven was filled with nitrogen gas to work under inert atmosphere. A 
self-designed support for a DLS laser remote source (from Cordouan Vascoflex or VascoKin) was fixed on the rotating table, Figure S3d. Figure S3e shows the DLS remote laser source fixed on the support after turning the table by $45^{\circ}$ and with a laser protection for security. As DLS measurements are fast (around $2 \mathrm{~min}$ for ionic liquid-based colloids analysed here) the samples were analysed during temperature changes to monitor temperature variations inside the sample. After obtaining a constant temperature, i.e., a constant DLS signal, the DLS remote laser was removed. The table was turned back to the initial position and the SANS measurement was performed. These steps were repeated at $27{ }^{\circ} \mathrm{C}, 70{ }^{\circ} \mathrm{C}, 135^{\circ} \mathrm{C}, 200{ }^{\circ} \mathrm{C}$ and back to $27^{\circ} \mathrm{C}$. As only classical circular quartz/spacer/quartz sandwich (see Figure S3a) could fit in this furnace and no change of the furnace was possible, adapted cells were developed, making it possible to heat liquid samples in the furnace. The cells are based on a Teflon spacer glued on quartz with a hole on the top to evacuate gases that may escape during the heating process (the cell is left open). Figure S3b shows a filled cell and in c) the cell was placed in the oven.

Leaks occurred with concentrated samples at high temperature as mentionned in the main text. Such a leak already appeared with dilute samples $\left(\Phi_{\mathrm{NP}} \approx 1 \mathrm{vol} \%\right)$ during the tests of the cell and was solved by adapting the nature of the ring spacer (and the nature of the materials). It appeared as a mixture of wetting phenomena and bubbling/degassing at high temperature, which was not occurring in the same way depending on the nature of the materials used to build the cell. This result shows however that these wetting phenomena and bubbling/degassing grow with $\Phi_{\mathrm{NP}}$.

The data presented come from three different neutron runs during which three configurations were used that slightly differed: 1st run) neutron wavelength $\lambda=6 \AA$, sample to detector distance $\mathrm{d}=1 \mathrm{~m} ; \lambda=6 \AA$, $\mathrm{d}=3 \mathrm{~m}$ and $\lambda=8.5 \AA \mathrm{d}=5 \mathrm{~m}$

2nd run) $\lambda=5 \AA, d=1 \mathrm{~m} ; \lambda=5 \AA, \mathrm{d}=3 \mathrm{~m}$ and $\lambda=8.5 \AA$, $\mathrm{d}=5 \mathrm{~m}$

3rd run) $\lambda=4 \AA, d=1 \mathrm{~m} ; \lambda=5 \AA, d=3 \mathrm{~m}$ and $\lambda=8.5 \AA, d=5 \mathrm{~m}$

DLS enables checking that thermal equilibrium is reached before measuring SANS. This is possible as the viscosity drastically varies with temperature which influences the correlation function. Hence, stability of the correlation function means that the viscosity and temperature are stable. DLS performed after SANS tells us whether some change occurred during the SANS measurement. In addition, agglomeration not visible by eye or large viscosity changes due to a chemical evolution also invisible by eye could be detected if curves drift to longer/shorter times. Precious beamtime could be thus saved by skipping some SANS measurements. Figure S4 shows an example for nanoparticle dispersions with $\mathrm{SBMIM}^{ \pm} \mathrm{TFSI}^{-}$interfacial species in EMIM TFSI. The change of the correlation functions $\mathrm{G}_{1}(\mathrm{t})$ is driven by viscosity, leading to a shift of the correlation function without distortion. Moreover, the two correlation functions before and after heating to $200{ }^{\circ} \mathrm{C}$ superimpose (ignoring a measurement problem due to vibrations leading to oscillations in the signal).

SANS provides information on the interparticle interactions, via $\mathrm{S}(\mathrm{Q} \rightarrow 0)$, shown as a function of temperature in Figure $\mathrm{S} 5$.

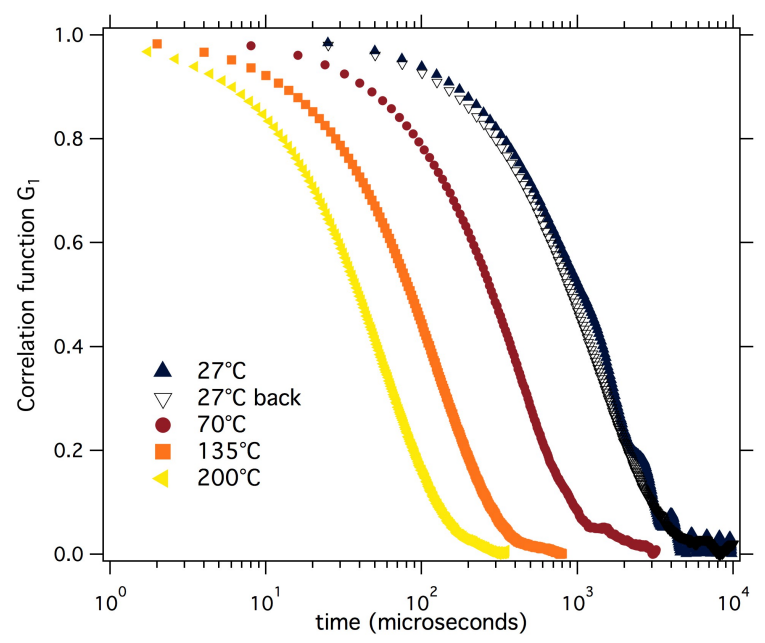

Figure S4. Dynamic light scattering (DLS) measurements for nanoparticle dispersions with $\left[\mathrm{SBMIM}^{ \pm}\right]=0.075 \mathrm{~mol} / \mathrm{L}$ in EMIM TFSI. Note that the shift of the curves is due to a change of viscosity because of the variation of temperature.

\section{S4.2 Thermogravimetric analysis (TGA)}

Isothermal and ramped temperature thermogravimetric analysis (TGA) were performed with a TGA 550 from TA Instruments. All samples (about $10-20 \mathrm{mg}$ with the mass precision $\pm 0.1 \mu \mathrm{g}$ ) were measured in platinum pans and some samples were also 


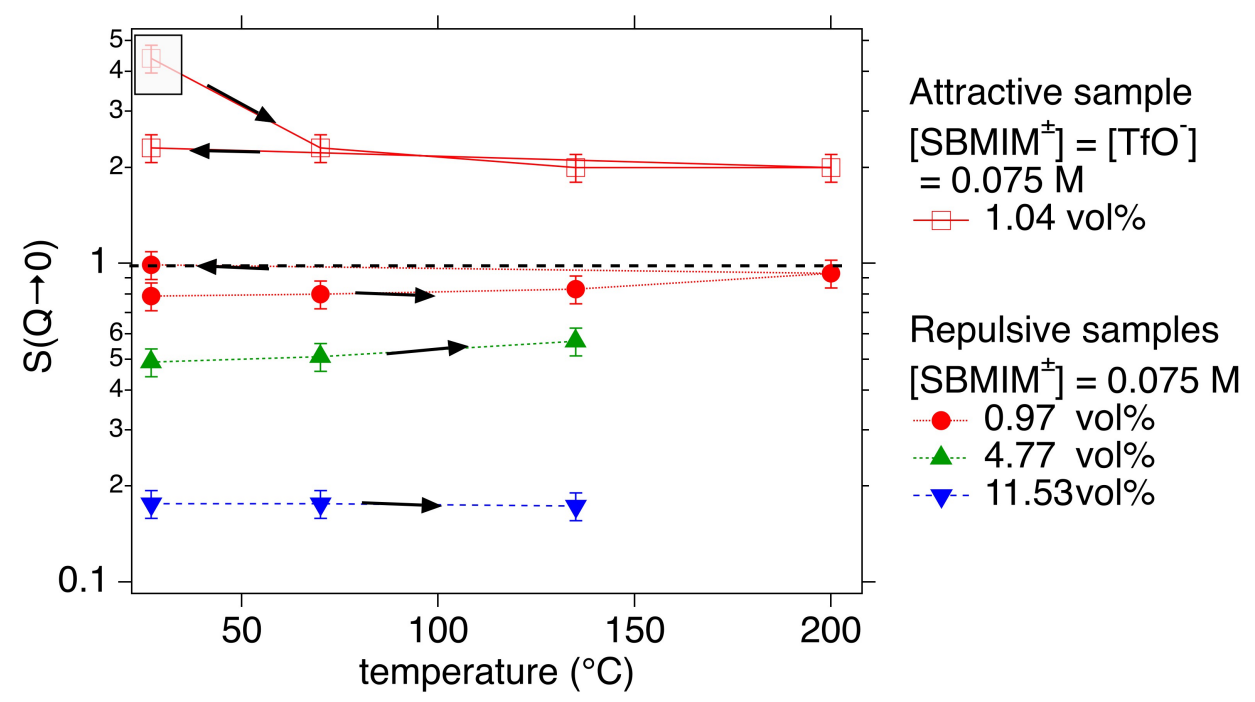

Figure S5. $\mathrm{S}(\mathrm{Q} \rightarrow 0)$ from SANS shown in Figure 5 of the main text as a function of temperature for the attractive and the repulsive samples. The lines are guide to the eye. The arrows indicate the heating cycle. Missing points are due to leakages as explained in the text. The grey box points to an experimental artefact, not observed with SAXS, and attributed to some pollution reversibly removed while heating.

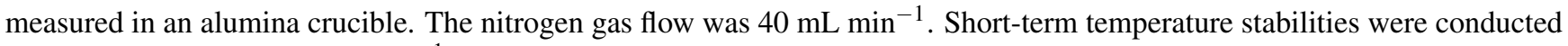
with a heating rate of $10{ }^{\circ} \mathrm{C} \mathrm{min}{ }^{-1}$ from room temperature up to $600{ }^{\circ} \mathrm{C}$. Long-term temperature stabilities were measured at isothermal mode for several hours at the specified isothermal temperature with a heating rate of $20^{\circ} \mathrm{C} \mathrm{min}{ }^{-1}$ from room temperature up to this temperature.

Figure S6 presents the raw ramped thermogravimetric analysis (TGA) corresponding to the data plotted in Figure 8 of the main text. It is used to determine $\mathrm{T}_{\text {start }}$, temperature at which the sample starts to loose weight, here defined for a derivative

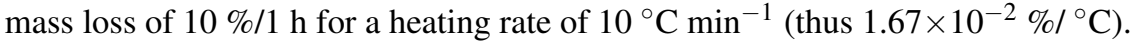

The results are summarized in Table $\mathrm{S} 1$ and compared with the data found in literature when possible.

Influence of the crucible: The influence of the nature of the crucible material has been tested in three samples (see Figure S7). If only a small shift is observed, between measurements in alumina and Pt crucibles, for a zwitterion $\mathrm{SBMIM}^{ \pm}$and the repulsive dispersion at $0.97 \mathrm{vol} \%$, on the contrary a strong distortion is observed with HSBMIM TFSI. As mentioned in the main text, HSMIM TFSI measured in classical Pt crucibles already decomposes at $30{ }^{\circ} \mathrm{C}$. This can be due to a catalysis due to $\mathrm{Pt}^{1}$. Note that alumina crucibles do not solve all difficulties, because ILs tend to escape from the crucibles, even if there is a cover. As these alumina crucibles have to be set in the Pt pans due to the conception of the device, a contact between the samples and the Pt can thus never be completely excluded. Nevertheless, the data are compared in the Pt crucibles, except HSBMIM TFSI which is presented in an alumina crucible (in Figure 8 of the main text).

Evaporation of the samples: although seldom considered, evaporation cannot always be neglected, even for ILs. Let us consider the case of EMIM TFSI. At $200{ }^{\circ} \mathrm{C}$, its vapour pressure is $0.02 \mathrm{~Pa}$ (from ref ${ }^{5}$ ), however a high amount of gas passes in TGA. In 10 hour isothermal measurement, $24 \mathrm{~L}$ of gas pass on 13 micro litres (around $20 \mathrm{mg}$ ) of sample, thus $8 \times 10^{5}$ $\mathrm{m}_{\text {gas }}^{3} m_{\text {ionicliquid }}^{-3} h^{-1}$. If the gas saturated immediately (which is far from being the case) this would lead to complete evaporation of EMIM TFSI in around 1 minute which explains why evaporation can be observed in some ionic liquids if the carrier gas absorbs at least a bit. Note that for EMIM TFO, the vapour pressure is $0.002 \mathrm{~Pa}, 10$ times lower. It means that the degradation can be overestimated from TGA measurements.

Isothermal TGA measurements are shown in Figure S8. For EMIM TFO, after a first heating to $160{ }^{\circ} \mathrm{C}$ at $20{ }^{\circ} \mathrm{C} \mathrm{min}{ }^{-1}$, the weight loss is measured during three hours at $160{ }^{\circ} \mathrm{C}$, followed by three hours at $180{ }^{\circ} \mathrm{C}$ and then ten hours at $200{ }^{\circ} \mathrm{C}$. The weight loss is lower than $0.1 \%$, showing that it is long-term stable at these temperatures, here on 16 hours. A Pt pan was used.

For EMIM TFSI and the ferrofluids, the samples were heated at $20{ }^{\circ} \mathrm{C} \mathrm{min}-1$ to $200{ }^{\circ} \mathrm{C}$ before measuring the weight at $200{ }^{\circ} \mathrm{C}$

\footnotetext{
${ }^{1}$ This has been observed for example in some ILs measured in aluminum, a material widely used for disposable pans ${ }^{9}$.
} 


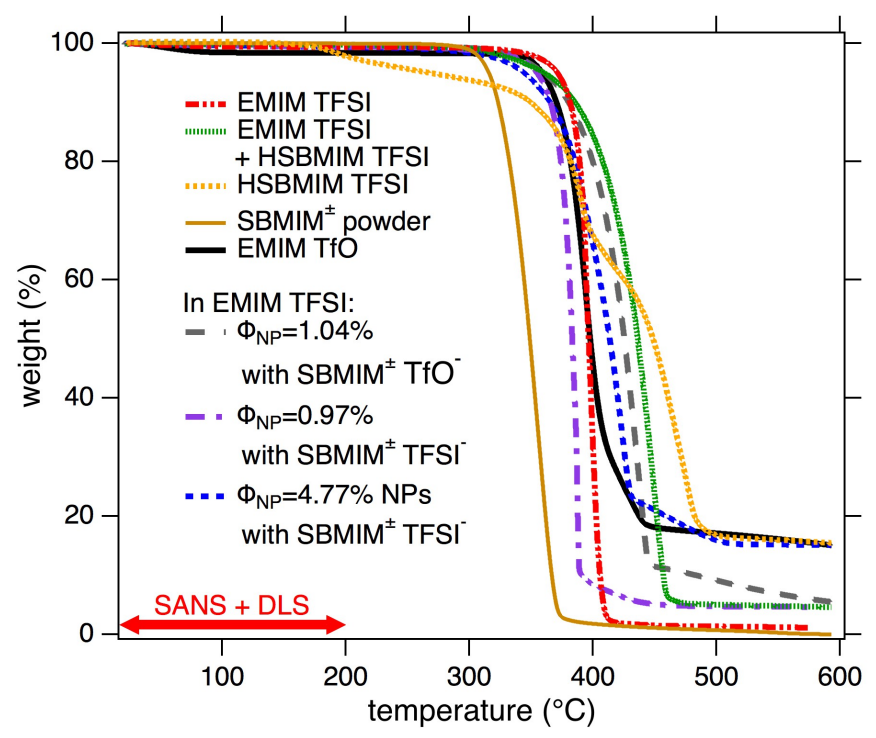

Figure S6. Ramped thermogravimetric analysis (TGA) measurements for the components of the nanoparticle dispersions in EMIM TFSI and for the resulting dispersions in EMIM TFSI. Pure EMIM TFSI and EMIM TfO are wet to mimic the worst case possible in the dispersions. Dry $\mathrm{SBMIM}^{ \pm}$and dry EMIM TFSI containing $2.5 \mathrm{wt} \%$ HSBMIM TFSI are also depicted, $2.5 \mathrm{wt} \%$ HSBMIM TFSI being the amount added while preparing the nanoparticle dispersions at $1 \mathrm{vol} \%$ nanoparticles. The final dispersions with $\Phi_{\mathrm{NP}}=1.04 \mathrm{vol} \%$ with $\left[\mathrm{SBMIM}^{ \pm}\right]=\left[\mathrm{TfO}^{-}\right]=0.075 \mathrm{~mol} / \mathrm{L}$ as well as $\Phi_{\mathrm{NP}}=0.97 \mathrm{vol} \%$ and a concentrated sample with $\Phi_{\mathrm{NP}}=4.77 \mathrm{vol} \%$ nanoparticles with $\left[\mathrm{SBMIM}^{ \pm}\right]=0.075 \mathrm{~mol} / \mathrm{L}$ are also plotted. Note that all measurements are here performed in Pt pans except HSBMIM TFSI, which is decomposed close to room temperature in a Pt pan (see Figure S7). The latter is measured in an alumina crucible. The corresponding derivatives used to define $\mathrm{T}_{\text {start }}$ are plotted in Figure 8 of the main text. The red arrow indicates the regions where SANS and DLS are performed.

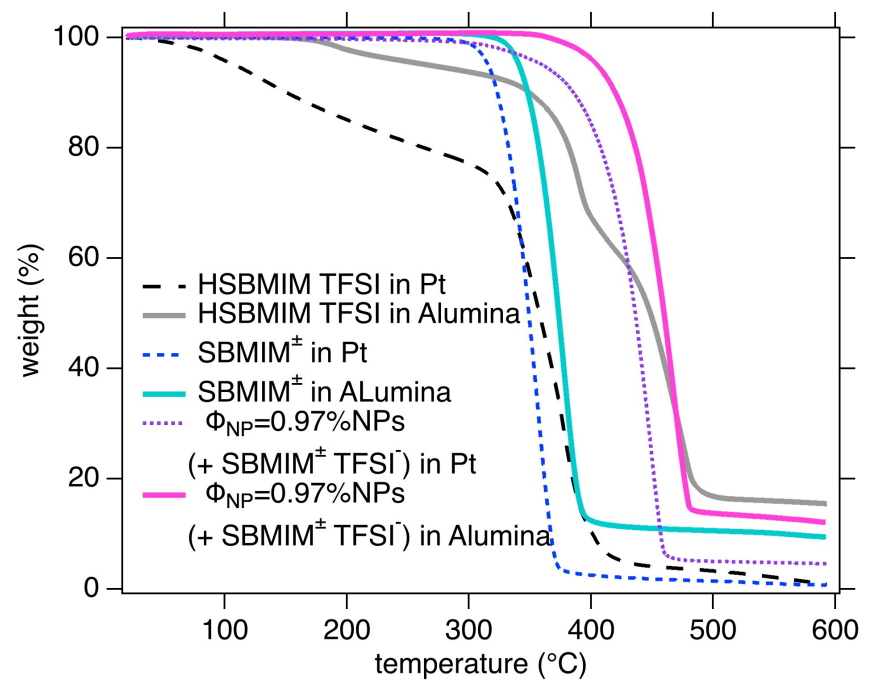

Figure S7. Ramped thermogravimetric analysis (TGA) measurements for 3 samples (see legend) either in a Pt pan or in an alumina crucible. Note that the alumina crucible has a cover, contrary to the Pt pan, which can limit evaporation if it occurs. However, this alumina crucible has still to be placed in the Pt pan and HSBMIM tends to escape from the crucible despite the cover.

during 15h. It was done in a Pt pan and in an alumina crucible. For the pure EMIM TFSI, the container has a weak influence, as opposed to the colloidal dispersions. This is attributed to the evolution of the additive HSBMIM in Pt pans shown in Figure S7. Therefore the more exact and relevant long measurements for our colloidal dispersions are the one performed in the alumina crucibles. 
Table S1. Critical temperatures $\left(\mathrm{T}_{\text {start }}\right.$ and $\left.\mathrm{T}_{\text {onset }}\right)$ in Celsius degrees deduced from ramped thermogravimetric analysis (TGA) measurements. $\mathrm{T}_{\text {start }}$ gives the temperature at which the sample starts to loose weight, here defined for a derivative weight loss of $1.67 \times 10^{-2} \% /{ }^{\circ} \mathrm{C}$. $\mathrm{T}_{\text {onset }}$ is defined by the linear extrapolation of the weight loss at decomposition to the baseline at zero weight loss. $\mathrm{T}_{0.01 / 10 h}\left(\right.$ resp. $\mathrm{T}_{0.02 / 10 h}$ ) is the temperature at which $1 \%$ (resp. $2 \%$ ) weight is lost after $10 \mathrm{~h}$. Tmax $\operatorname{mol}_{0.01 / \text { year }}$ is the temperature at which $1 \%$ weight is lost after one year. All temperatures are given in ${ }^{\circ} \mathrm{C}$ and the error is $\pm 10 .{ }^{i}$ for ionic liquid containing water; ${ }^{e}$ Losses due to evaporation are removed.

\begin{tabular}{|c|c|c|c|c|c|c|c|}
\hline & \multicolumn{3}{|c|}{ measured } & \multicolumn{4}{|c|}{ literature } \\
\hline & $\mathrm{T}_{\text {start }}$ & $\mathrm{T}_{\text {onset }}$ & $\begin{array}{l}\text { weight loss after } \\
10 \text { h at } 200{ }^{\circ} \mathrm{C}\end{array}$ & $\mathrm{T}_{\text {start }}$ & $\mathrm{T}_{\text {onset }}$ & $\begin{array}{l}\mathrm{T}_{0.01 / 10 h} \\
\text { or } \mathrm{T}_{0.02 / 10 h}\end{array}$ & $\operatorname{Tmax}_{0.01 / \text { year }}$ \\
\hline $\begin{array}{l}\Phi_{\mathrm{NP}}=1.04 \mathrm{vol} \% \\
{\left[\mathrm{SBMIM}^{ \pm}\right]=\left[\mathrm{TfO}^{-}\right]} \\
=0.075 \mathrm{~mol} / \mathrm{L}\end{array}$ & 303 & 393 & & - & - & & \\
\hline $\begin{array}{l}\Phi_{\mathrm{NP}}=0.97 \mathrm{vol} \% \\
{\left[\mathrm{SBMIM}^{ \pm}\right]=0.075 \mathrm{~mol} / \mathrm{L}}\end{array}$ & 303 & 374 & & - & - & & \\
\hline $\begin{array}{l}\Phi_{\mathrm{NP}}=4.77 \mathrm{vol} \% \\
{\left[\mathrm{SBMIM}^{ \pm}\right]=0.075 \mathrm{~mol} / \mathrm{L}}\end{array}$ & 283 & 377 & & - & - & & \\
\hline EMIM TfO & $333^{i}$ & $373^{i}$ & $<0.1 \%$ & & $348^{5}$ & & $185^{5 e}$ \\
\hline EMIM TFSI & $322^{i}$ & $386^{i}$ & $<0.1 \%^{6}$ & $320^{7}$ & $410-450^{7-9}$ & $222^{7}$ or $252^{6}$ & $286^{5 e}$ \\
\hline $\begin{array}{l}\text { EMIM TFSI } \\
+2.5 \mathrm{wt} \% \\
\text { HSBMIM TFSI }\end{array}$ & 295 & 401 & & - & - & & \\
\hline SBMIM $^{ \pm}$ & 274 & 325 & & & & & \\
\hline HSBMIM TFSI & 158 & 305 & & & & & \\
\hline $\mathrm{HSBMIM} \mathrm{HSO}_{4}$ & & & & & $327^{10}$ & & \\
\hline HSPMIM TfO & & & & & $288^{11}$ & & \\
\hline
\end{tabular}

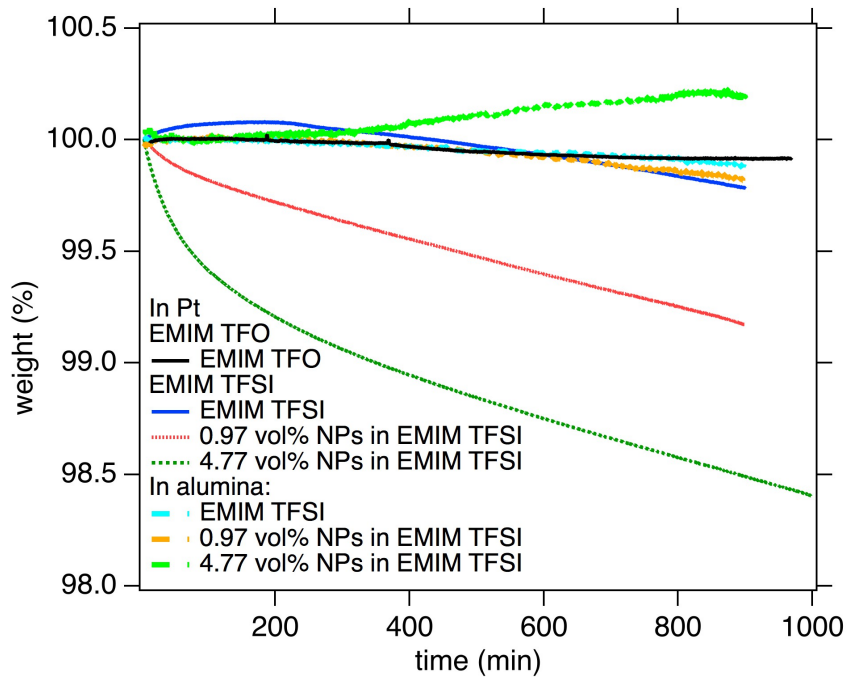

Figure S8. Isothermal thermogravimetric analysis (TGA) measurements for EMIM TfO, EMIM TFSI and the derived colloidal dispersions in two different containers, Pt or alumina crucibles. See legend and text for details.

\section{References}

1. Frot, D., Patin, P., Woodley, B. \& Pinier, F. Détecteur d'Intensité Lumineuse Diffusée par des Films de Milieux Colloidaux. European Patent Office 0-654-661-A1 (1994).

2. Paduszyński, K. \& Domańska, U. Viscosity of Ionic Liquids: An Extensive Database and a New Group Contribution Model Based on a Feed-Forward Artificial Neural Network. Journal Chemical Information Modeling 54, 1311-1324, DOI: 10.1021/ci500206u (2014). 
3. Fiuza, T. et al. Thermodiffusion anisotropy under a magnetic field in ionic liquid-based ferrofluids. Soft Matter 17, 4566-4577, DOI: 10.1039/D0SM02190C (2021).

4. Schwertmann, U. \& Cornell, R. M. Iron Oxides in the Laboratory: Preparation and Characterization (John Wiley \& Sons, 2008). DOI:10.1002/9783527613229.

5. Heym, F., Etzold, B. J. M., Kern, C. \& Jess, A. Analysis of evaporation and thermal decomposition of ionic liquids by thermogravimetrical analysis at ambient pressure and high vacuum. Green Chem. 13, 1453, DOI: 10.1039/c0gc00876a (2011).

6. Villanueva, M., Coronas, A., García, J. \& Salgado, J. Thermal Stability of Ionic Liquids for Their Application as New Absorbents. Ind. Eng. Chem. Res. 52, 15718-15727, DOI: 10.1021/ie401656e (2013).

7. Cao, Y. \& Mu, T. Comprehensive Investigation on the Thermal Stability of 66 Ionic Liquids by Thermogravimetric Analysis. Ind. Eng. Chem. Res. 53, 8651-8664, DOI: 10.1021/ie5009597 (2014).

8. Awad, W. H. et al. Thermal degradation studies of alkyl-imidazolium salts and their application in nanocomposites. Thermochimica Acta 409, 3-11, DOI: 10.1016/S0040-6031(03)00334-4 (2004).

9. Ngo, H. L., LeCompte, K., Hargens, L. \& McEwen, A. B. Thermal properties of imidazolium ionic liquids. Thermochimica Acta 357-358, 97-102, DOI: 10.1016/S0040-6031(00)00373-7 (2000).

10. Gui, J. et al. Selective alkylation of phenol with tert-butyl alcohol catalyzed by Brönsted acidic imidazolium salts. Journal Molecular Catalysis A: Chemical 225, 27-31, DOI: 10.1016/j.molcata.2004.08.026 (2005).

11. Amarasekara, A. S. \& Owereh, O. S. Thermal properties of sulfonic acid group functionalized Brönsted acidic ionic liquids. J Therm Anal Calorim 103, 1027-1030, DOI: 10.1007/s10973-010-1101-5 (2011). 